\title{
Monetary Policy for a Bubbly World
}

\author{
VLADIMIR ASRIYAN AND LUCA FORNARO \\ CREI, Universitat Pompeu Fabra and Barcelona GSE \\ ALBERTO MARTIN \\ ECB, CREI, and Barcelona GSE \\ and \\ JAUME VENTURA \\ CREI, Universitat Pompeu Fabra and Barcelona GSE
}

First version received June 2019; Editorial decision March 2020; Accepted July 2020 (Eds.)

\begin{abstract}
What is the role of monetary policy in a bubbly world? To address this question, we study an economy in which financial frictions limit the supply of assets. The ensuing scarcity generates a demand for "unbacked" assets, i.e., assets that are backed only by the expectation of their future value. We consider two types of unbacked assets: bubbles, which are created by the private sector, and money, which is created by the central bank. Bubbles and money share many features, but they also differ in two crucial respects. First, while the rents from the creation of bubbles accrue to entrepreneurs and foster investment, the rents from money creation accrue to the central bank. Second, while bubbles are driven by market psychology, and can rise and fall according to the whims of the market, money is under the control of the central bank. We characterize the optimal monetary policy and show that, through its ability to supply assets, monetary policy plays a key role in the bubbly world. The model sheds light on the recent expansion of central bank liabilities in response to the bursting of bubbles.
\end{abstract}

Key words: Bubbles; Financial frictions; Optimal monetary policy; Liquidity trap.

JEL Codes: E32, E44, O40

\section{INTRODUCTION}

We live in a world of low interest rates and volatile asset values. Over the last three decades, real interest rates have declined continuously throughout advanced economies, having been in negative territory throughout much of the last decade. Although there are different views as to the ultimate cause of this decline, most agree that it reflects some form of asset scarcity, i.e., an increased demand for assets that raises their price thereby depressing returns. Over these same three decades, Japan, the U.S., and parts of the Eurozone have all exhibited large booms and busts in asset prices with significant consequences for economic activity. The long slump that characterized Japan during the 1990s, as well as the most recent recessions in the U.S. and the

The editor in charge of this paper was Veronica Guerrieri. 
Eurozone periphery in the aftermath of the global financial crisis, all coincided with the bursting of real estate and equity bubbles.

How should monetary policy be conducted in this bubbly world? Most of the debate surrounding this question has focused on the ability of interest rate policy to prevent or control the appearance and growth of bubbles. But there is an alternative aspect of policy that was central to all of these episodes: the collapse of asset prices was accompanied by a fall into a liquidity trap and a substantial growth of central bank balance sheets. As the value of private assets evaporated, market participants turned to central banks for stores of value, which supplied them by expanding the monetary base (mostly in the form of reserves, but also through cash). In the U.S., for instance, the monetary base grew 5-fold, from approximately $\$ 880$ billion in 2008 to a peak of $\$ 4.1$ trillion in 2014. The Eurozone's monetary base experienced a similar expansion, from approximately $€ 800$ billion in 2008 to $€ 3.5$ trillion in 2018 . This suggests that a key aspect of monetary policy in dealing with bubbles and their aftermath has been precisely to supply stores of value. Yet this role is completely absent in the New Keynesian paradigm that has dominated monetary economics over the last few decades, which emphasizes the role of money as a unit of account and of nominal rigidities as drivers of monetary transmission (e.g. Galí, 2009; Woodford, 2011). Without denying the usefulness of this paradigm, the events outlined above suggest that a shift in perspective may be called upon. In a bubbly world (i.e. a world of low interest rates, and large booms and busts in asset prices), we can no longer disregard the role of money as a store of value, and the role of monetary policy as a supplier of stores of value. This raises a number of fundamental questions. When is money valuable as a store of value? How is this value connected to the rise and bursting of bubbles? Can the central bank always supply stores of value? If so, how much should it supply? This article develops a framework to address these questions.

To be sure, we are not the first to think of money as a store of value, as there is an old tradition in economics of adopting this perspective (e.g. Wallace, 1981). We build on that tradition and its insights but combine it with the recent literature on asset bubbles and financial frictions (e.g. Martin and Ventura, 2018). The framework that emerges provides a unified view on the connection between low interest rates, booms, and busts in asset prices, and the role of money as a store of value. In particular, it enables us to study the similarities and differences between money and bubbles, their interaction, and the conduct of monetary policy in a bubbly world. In order to make the results as stark as possible, we completely neglect the role played by money as a unit of account and by nominal rigidities emphasized in the literature. Nonetheless, as we shall see, monetary policy retains a powerful role.

The main elements of this view are easily explained. Consider an overlapping-generations world, in which some agents (entrepreneurs) want to borrow because they have productive investment opportunities, and other agents (savers) want to save because they do not have them. Normally, entrepreneurs would supply "backed" assets, i.e., assets backed by the fruits of their investment, and savers would demand these assets as stores of value. Financial frictions, though, restrict the supply of backed assets and depress the interest rate. This opens the door for "unbacked"assets to be issued, i.e., assets that are backed only by expectations of their future value. Unbacked assets can be thought of as pyramid schemes, in which present contributions to the schemes (present purchases of the asset) give the right to receive future contributions (future purchases of the asset). As long as the expected return to these assets or pyramid schemes is sufficiently high, agents will be willing to hold them in equilibrium.

The dynamics of unbacked assets are driven by two forces, with differing effects on economic activity. First, their creation generates a wealth effect. New unbacked assets generate a rent for their creators because they are costless to produce and yet they have positive market value. For example, if an entrepreneur issues debt that is unbacked because the market expects it to be rolled over indefinitely, then she receives a pure rent. Second, the existence of unbacked assets generates 
an overhang effect. Old unbacked assets must be purchased and this diverts resources that could have been used for productive investment. In our example, the savers that actually finance the roll-over of the entrepreneur's debt must divert their funds from other uses. In short, the wealth effect of unbacked assets depends on their issuer, whereas the overhang effect depends on their buyer.

We consider two types of unbacked assets. The first one is created by private entrepreneurs, and we refer to it as a bubble. The second one is created by a public central bank, and we refer to it as money. Money can be valued as an asset if its expected rate of return (the inverse of the rate of inflation) equals the real interest rate. In this case, the economy is in a liquidity trap. Both bubbles and money have wealth and overhang effects, but they differ in two crucial respects. First, bubbles are superior to money because their wealth effect accrues to entrepreneurs and, as a result, they foster investment. The wealth effect of money (i.e. seigniorage) accrues instead to the central bank, and its effect depends on how it is distributed among economic agents. Second, bubbles are inferior to money because they are driven by market psychology, so that their behaviour may be volatile and unpredictable, whereas money is under the control of the central bank. Ultimately, nothing guarantees that the size of bubbles supplied by the market will be optimal. We analyse the role of monetary policy in this bubbly world. To constrain the role of policy as much as possible, we restrict the central bank's actions along three key dimensions. First, we assume that the central bank lacks fiscal backing, so that it cannot use tax proceeds to back the value of money. Second, we assume that the central bank is constrained in its use of seigniorage, so that it cannot choose how to distribute this revenue between entrepreneurs and savers. Finally, we assume that the central bank cannot affect market psychology, so that it must take the evolution of private bubbles as given. Despite these restrictions, we show that monetary policy has the ability to supply unbacked assets and - through this ability—plays a powerful role.

We find two main results. First, we show that the central bank can always intervene in the bubbly world, adjusting the money supply to provide unbacked assets over and above those supplied by private bubbles. Should it choose to do so, moreover, we show that the central bank can fully stabilize the economy's total supply of unbacked assets at a target of its choice! The choice of target is constrained by the market psychology that governs private bubbles, however. In particular, the central bank can only add to- but not subtract from-the unbacked assets supplied by private bubbles, and it is limited to implementing policies that guarantee non-explosive paths for these bubbles.

Second, we show that the central bank should intervene in the bubbly world. We characterize an optimal monetary policy that-by adjusting the supply of unbacked assets-raises the consumption of all generations along all histories. To derive this result, we identify sequences of unbacked assets that are Pareto optimal, in the sense that-given any such sequence-it is impossible to raise the consumption of any one generation without reducing it for some other generation. The intuition here is the familiar one, i.e., unbacked assets are beneficial insofar as their overhang effect crowds out dynamically inefficient investments. By adjusting its supply of unbacked assets, monetary policy can ensure Pareto optimality.

In a nutshell, the main takeaway of the theory is that central banks have a key role to play in the bubbly world: to supply assets. This resonates well with the conduct of monetary policy in the wake of the global financial crisis, when central banks expanded their balance sheets in response to the bursting of bubbles. But, it is also quite different. In a standard balance sheet expansion, the central bank issues some assets and purchases others, leaving the net supply of assets available to the private sector unchanged. In the bubbly world, instead, the key aspect of welfare-enhancing interventions is that they expand the net supply of assets available to the private sector, thereby soaking up inefficient investment. 
Finally, the theory also clarifies how the central bank's ability to supply assets is shaped by different aspects of its institutional design. First, although the absence of fiscal backing does not limit the central bank's ability to supply assets, it may lead to volatile inflation. The reason is that the central bank can always expand the supply of real balances when there is demand for unbacked assets, but - without fiscal backing - the only way of reducing real balances when there is no such demand is by inflating their value away. Thus, if inflation volatility is costly, so is asset-supply stabilization in the absence of fiscal backing. Second, the distribution of seigniorage is crucial in shaping the aggregate effects of monetary policy. In our benchmark, bubbles outperform monetary policy because the central bank cannot target the distribution of seigniorage to entrepreneurs. If it could do so, seigniorage could be used to foster investment and monetary policy could potentially replicate the effects of private bubbles. Somewhat paradoxically, we show that this might come at the cost of creating the volatility typically associated with bubbles. Finally, the interaction between monetary policy and market psychology is central. Our benchmark shows that monetary policy is powerful even when the central bank cannot affect market psychology: if it could do so, monetary policy would be even more powerful in the sense that it could prevent "undesirable" bubbles altogether.

\subsection{Related literature}

We build on the traditional models of rational bubbles (Samuelson, 1958; Tirole, 1985) and on the recent literature connecting bubbles and credit (Caballero and Krishnamurthy, 2006; Farhi and Tirole, 2011; Martin and Ventura, 2012, 2015, 2016; Miao and Wang, 2012, 2018). Although we share many similarities with these frameworks, these papers do not study monetary policy. A small literature has considered the role of monetary policy in economies with rational bubbles, but it abstracts from credit and financial frictions (Galí, 2014, 2019). We are thus among the first to provide a model of rational bubbles, credit cycles, and monetary policy. ${ }^{1}$

Our model draws heavily on the framework of Martin and Ventura $(2012,2016)$. They showed that financial frictions can give rise to bubbles, and that bubbles can expand economic activity by relaxing borrowing constraints. They also argued that governments could use their ability to tax to sustain equilibrium bubbles. In this article, we substantially enhance our general understanding of the framework. First, we extend the model along a key dimension by introducing money and by studying the conduct of monetary policy. We show that, even without taxation or fiscal transfers, a central bank can use monetary policy to control the supply of assets. Second, we characterize Pareto optimal monetary policies, i.e., the optimal control of public bubbles in response to fluctuations in private bubbles. To the best of our knowledge, this is the first paper in the literature to do so.

Our work is also closely related to the literature on the "financial accelerator," in which borrowers' net worth in general-and asset prices in particular-determine the level of financial intermediation and economic activity (Bernanke and Gertler, 1989; Kiyotaki and Moore, 1997). Building on this literature, some recent work has shown that balance sheet policies by the central bank can help alleviate financial frictions during periods of financial stress (Gertler and Kiyotaki, 2010; Gertler and Karadi, 2011; Del Negro et al., 2017). Our article differs from this body of work in two key dimensions. First, in our theory net worth and asset prices are not just a transmission channel for fundamental shocks: instead, they are driven by expectations and can therefore be a source of shocks themselves. Second, in these models the central bank expands its balance sheet

1. In contemporaneous work, Wang et al. (2017) also study the role of monetary policy in a world with rational bubbles. However, they do not consider the central bank's role as a supplier of stores of value. 
to increase lending to constrained agents, or to sustain asset prices and thus the value of their collateral. We emphasize instead a different role for balance sheet policies. In our theory, the economy's supply of assets is scarce due to financial frictions, leading to inefficient investment. Against this background, the central bank expands its balance sheet to increase the economy's stock of assets and to reduce inefficient investment. We thus show that a balance sheet expansion by the central bank might increase welfare, even if it does not lead to an increase in borrowers' net worth or in the value of their collateral.

Our article also contributes to the vast literature on liquidity traps (Krugman, 1998; Eggertsson and Woodford, 2003; Di Tella, 2020). In particular, it is related to the work identifying financial shocks as the source of liquidity traps (Eggertsson and Krugman, 2012; Guerrieri and Lorenzoni, 2012). Different from existing work, we provide a framework where financial shocks arise due to changes in expectations. Our article is also closely related to the literature on secular stagnation (Hansen, 1939; Summers, 2013; Krugman, 2013), which is the idea that structural factors can depress interest rates and generate long-lasting liquidity traps. A recent literature has formalized the secular stagnation hypothesis in microfounded frameworks (Benhabib et al., 2001; Caballero and Farhi, 2018; Benigno and Fornaro, 2018; Bacchetta et al., 2019; Eggertsson et al., 2019). We contribute to this literature by showing that a long-lasting liquidity trap can be the outcome of a bubble crash, which depresses the economy's supply of assets.

\section{A MODEL OF MONEY AND BUBBLES}

We develop an overlapping-generations model with bubbles and money. Entrepreneurs invest and raise funds by issuing debts and bubbles. The former are backed by future output, while the latter are not. Savers purchase these assets, and they might also hold money if inflation is low enough. The focus of the model is on the interaction between money and bubbles. Both are unbacked assets, but they differ in two crucial aspects. First, bubbles are issued by the entrepreneurs, while money is issued by the central bank. Second, there is an arbitrarily small but stable demand for money, while there is no such demand for bubbles.

\subsection{Setup}

We consider an economy populated by overlapping generations of individuals that live for two periods. All generations have the same size, which is normalized to one. Time is discrete and infinite, $t \in\{0, \ldots, \infty\}$. This economy does not experience technology or preference shocks, but it displays stochastic equilibria with asset price and monetary policy shocks. We define $h_{t}$ as the realization of these shocks in period $t ; h^{t}$ as a history of shocks until period $t$, that is, $h^{t}=$ $\left\{h_{0}, h_{1}, \ldots, h_{t}\right\}$; and $H_{t}$ as the set of all possible histories until period $t$.

The technology to produce goods takes the standard Cobb-Douglas form:

$$
Y_{t}=\left(\gamma^{t} \cdot L_{t}\right)^{1-\alpha} \cdot K_{t}^{\alpha},
$$

with $\alpha \in(0,1)$, where $Y_{t}, L_{t}$, and $K_{t}$ denote the output, the labour force, and the capital stock in the economy. Labour productivity grows at rate $\gamma>1$. Each generation supplies one unit of labour during youth, so that $L_{t}=1$. Capital fully depreciates in one period. To produce one unit of capital for period $t+1$, one unit of goods must be invested in period $t$. Factor markets are 
competitive so that all factors are employed and paid their marginal products:

$$
\begin{gathered}
W_{t}=(1-\alpha) \cdot \gamma^{(1-\alpha) \cdot t} \cdot K_{t}^{\alpha} \\
R_{t}^{K}=\alpha \cdot \gamma^{(1-\alpha) \cdot t} \cdot K_{t}^{\alpha-1}
\end{gathered}
$$

where $W_{t}$ and $R_{t}^{K}$ are the wage and the rental rate, respectively.

Each generation contains two agent types: entrepreneurs and savers. Both types maximize old-age consumption:

$$
U_{t}^{i}=E_{t} C_{t+1}^{i}
$$

where $U_{t}^{i}$ and $C_{t+1}^{i}$ are the utility and consumption of agent $i$ of generation $t .^{2}$ Thus, young agents save their entire income and choose those assets that offer the highest expected return.

All agents are endowed with one unit of labour when young, but they differ in terms of the assets that they can hold and issue. While entrepreneurs can hold capital and issue private assets in the financial market, savers can do neither. Throughout, we assume that the share of entrepreneurs $\varepsilon$ is small, i.e., $\varepsilon<\frac{1}{2}$.

Entrepreneurs issue two types of assets. The first one is debt backed by the return to a unit of capital. Creating these debts costs a fraction $\phi$ of the investment. Thus, the return to these debts is given by $\frac{R_{t+1}^{K}}{1+\phi}$. One interpretation of the intermediation $\operatorname{cost} \phi$ is that there is some need to monitor or screen entrepreneurs. ${ }^{3}$ The second type of asset is unbacked, and we refer to it as a bubble. Let $B_{t}$ be the value of all bubbles started by earlier generations of entrepreneurs, i.e., "old" bubbles. Let $N_{t}$ be the value of all bubbles started by the current generation of entrepreneurs, i.e., "new" bubbles. Free-disposal implies that old and new bubbles must be non-negative: $B_{t} \geq 0$ and $N_{t} \geq 0$. The return to holding all bubbles from $t$ to $t+1$ is given by $\frac{B_{t+1}}{B_{t}+N_{t}}$. To see this, note that the value of all bubbles traded in period $t$ is $B_{t}+N_{t}$ in period $t$, and $B_{t+1}$ in period $t+1$.

There is a central bank that issues unbacked money. Let $M_{t}$ be the real value of money in period $t$. Let $\mu_{t+1}$ be the (gross) growth rate of nominal money from $t$ to $t+1$. Thus, the return to holding money from $t$ to $t+1$ is given by:

$$
\pi_{t+1}^{-1}=\mu_{t+1}^{-1} \cdot \frac{M_{t+1}}{M_{t}}
$$

where $\pi_{t+1}$ is the (gross) inflation rate from period $t$ to period $t+1$. Seigniorage (or the value of "new" money printed in period $t$ ) is given by $\frac{\mu_{t}-1}{\mu_{t}} \cdot M_{t}$. The rest is "old" money printed in earlier periods. New money is distributed lump-sum among the old. Since the central bank does not have the ability to tax, seigniorage must be non-negative, i.e., $\mu_{t} \geq 1$ for all $t$ and $h^{t}$.

2. All variables are indexed by $h^{t}$. We could be more explicit about this dependence by writing $C_{t+1, h^{t+1}}^{i}$, but we prefer to streamline the notation and omit the history sub-index.

3. For example, suppose each entrepreneur has access to an unbounded pool of investment projects. Each project allows an entrepreneur to convert a unit of the consumption good into a unit of productive capital. The projects, however, also allow the entrepreneur to divert all the returns to capital for private consumption unless a monitoring cost is paid. This cost consists of $\phi$ units of consumption good per project. It is then straightforward to show that: (i) the equilibrium return to projects financed by savers is $R_{t+1}^{K} /(1+\phi)$, since backed debt contracts are only possible if monitoring costs are paid; and (ii) the equilibrium return to projects financed by entrepreneurs is $R_{t+1}^{K}$, since monitoring is not needed for self-financed projects. 
For technical reasons, namely to generate a positive demand for money, we assume that there is a small subset of savers, with mass $v \approx 0$, who do not participate in financial markets and use all their labour income to purchase money. We refer to these savers as money holders. ${ }^{4}$

\subsection{The value of money and bubbles: three regimes}

Let $R_{t+1}$ be the real interest or the required expected return to assets in the financial market. Then, the value of bubbles and money is determined as follows:

$$
\begin{aligned}
& B_{t}+N_{t}=\frac{1}{R_{t+1}} \cdot E_{t} B_{t+1}, \\
& M_{t}=\max \left\{v \cdot W_{t}, \frac{1}{R_{t+1}} \cdot E_{t}\left\{\frac{M_{t+1}}{\mu_{t+1}}\right\}\right\} .
\end{aligned}
$$

Equation (6) says that the value of bubbles today is their expected value tomorrow discounted. Equation (7) says that, if the expected value of money tomorrow discounted is large enough, savers hold money and its value exceeds the savings of money holders: $M_{t}>v \cdot W_{t}$. In this case, $E_{t} \pi_{t+1}^{-1}=R_{t+1}$, and we say that the economy is inside the liquidity trap. If instead the expected value of money tomorrow discounted is not large enough, savers do not hold money and $M_{t}=$ $v \cdot W_{t}$. In this case, $E_{t} \pi_{t+1}^{-1}<R_{t+1}$, and the economy is outside the liquidity trap.

This economy can be in one of three regimes depending on the value of unbacked assets. In the first regime, unbacked assets fall short of the combined savings of money holders and savers, i.e., $M_{t}+B_{t}+N_{t}<(1-\varepsilon) \cdot W_{t}$. Savers hold backed assets and, possibly, also some unbacked assets. Entrepreneurs invest their wage plus the proceeds from selling assets. Thus, we have that:

$$
\begin{aligned}
& K_{t+1}=\varepsilon \cdot W_{t}+N_{t}+\frac{(1-\varepsilon) \cdot W_{t}-M_{t}-B_{t}-N_{t}}{1+\phi}, \\
& R_{t+1}=\frac{R_{t+1}^{K}}{1+\phi} .
\end{aligned}
$$

The capital stock equals the wage of the entrepreneurs plus the revenue raised by selling assets. Since bubbles are costless to issue, they generate one unit of capital per unit sold. Since debts are costly to issue, they generate only $(1+\phi)^{-1}$ units of capital per unit sold. Since the marginal buyer of unbacked assets is a saver, the required return to unbacked assets is $\frac{R_{t+1}^{K}}{1+\phi}$.

In the second regime, unbacked assets equal the combined savings of money holders and savers, i.e., $M_{t}+B_{t}+N_{t}=(1-\varepsilon) \cdot W_{t}$. In this regime, savers hold only unbacked assets. Entrepreneurs do not hold unbacked assets and invest their wage plus the proceeds from selling bubbles. Thus, we have that:

$$
\begin{aligned}
& K_{t+1}=\varepsilon \cdot W_{t}+N_{t}, \\
& R_{t+1} \in\left[\frac{R_{t+1}^{K}}{1+\phi}, R_{t+1}^{K}\right] .
\end{aligned}
$$

The capital stock equals the wage of the entrepreneurs plus the revenue from selling bubbly assets. The value of unbacked assets has grown large enough to crowd out all debts. Since the marginal

4. All monetary models introduce a small (transactions-motivated) demand for money. This is often done by including money in the utility function, or by adding a cash-in-advance constraint. One can interpret our money holders in one of these two ways. Or one can interpret them as agents that have a high cost of participating in the financial market. 
buyer of unbacked assets depends on the direction of the change, the required return to unbacked assets is now higher than $\frac{R_{t+1}^{K}}{1+\phi}$, but lower than $R_{t+1}^{K}$.

In the third regime, unbacked assets exceed the combined savings of money holders and savers, i.e., $M_{t}+B_{t}+N_{t}>(1-\varepsilon) \cdot W_{t}$. In this regime, both savers and entrepreneurs hold unbacked assets. Thus, we have that:

$$
\begin{aligned}
& K_{t+1}=W_{t}-M_{t}-B_{t}, \\
& R_{t+1}=R_{t+1}^{K} .
\end{aligned}
$$

The capital stock equals the wage of the entrepreneurs, plus the revenue from selling bubbles minus their purchases of money and bubbles. The value of unbacked assets has grown so large that it does not only crowd out all debts, but it also crowds out some investments financed by the entrepreneurs themselves. Since the marginal buyer of unbacked assets is now an entrepreneur, the required return to unbacked assets is $R_{t+1}^{K}$.

We summarize this discussion as follows:

$$
\begin{gathered}
K_{t+1}=\min \left\{\varepsilon \cdot W_{t}+N_{t}+\frac{(1-\varepsilon) \cdot W_{t}-M_{t}-B_{t}-N_{t}}{1+\phi}, W_{t}-M_{t}-B_{t}\right\}, \\
R_{t+1} \begin{cases}=\frac{R_{t+1}^{K}}{1+\phi} & \text { if } M_{t}+B_{t}+N_{t}<(1-\varepsilon) \cdot W_{t}, \\
\in\left[\frac{R_{t+1}^{K}}{1+\phi}, R_{t+1}^{K}\right. & \text { if } M_{t}+B_{t}+N_{t}=(1-\varepsilon) \cdot W_{t}, \\
=R_{t+1}^{K} & \text { if } M_{t}+B_{t}+N_{t}>(1-\varepsilon) \cdot W_{t} .\end{cases}
\end{gathered}
$$

Equations (14) and (15) show the evolution of the capital stock and the real interest rate as a function of factor prices and the value of unbacked assets.

We define a competitive equilibrium of this economy as an initial condition $K_{0}$ and a nonnegative sequence for $\left\{W_{t}, R_{t}^{K}, B_{t}, N_{t}, M_{t}, \mu_{t}, K_{t}, R_{t}\right\}$ that satisfies Equations (2)-(3), (6)-(7), and (14)-(15) and $K_{t}>0$ and $\mu_{t} \geq 1$ for all $t$ and $h^{t} \in H_{t}$. This guarantees that all individuals maximize and all markets clear in all periods and histories.

It is worth here to say a few words about the sources of uncertainty and, therefore, the collection of sets $H_{t}$ (one for each $t$ ) that need to be considered. In period $t$, all individuals know $\left\{B_{t}, N_{t}, M_{t}, \mu_{t}, K_{t}\right\}$. It follows from Equations (2)-(3) and (14)-(15) that $K_{t+1}$ must be known also. ${ }^{5}$ There are however, two potential sources of uncertainty that individuals could face. The first one is the value of bubbles and money tomorrow, i.e., $\left\{B_{t+1}, N_{t+1}, M_{t+1}\right\}$. As we shall see, under some parameter conditions, there are random sequences for these variables that satisfy Equations (6)-(7). When this is the case, we say that there are asset price shocks since individuals cannot perfectly forecast the value of future bubbles and money. The second potential source of uncertainty is future money growth, i.e., $\left\{\mu_{t+1}\right\}$. Monetary policy could be uncertain because it responds to asset price shocks. Monetary policy could also add additional sources of uncertainty. When this is the case, we say that there are monetary policy shocks since individuals cannot perfectly forecast future money growth conditional on asset price shocks. Thus, the collection of sets $H_{t}$ must be specified for each competitive equilibrium.

5. Note that factor prices and the real interest rate are functions of $K_{t}$ and $t$ only. Thus, it is enough to focus on $\left\{B_{t}, N_{t}, M_{t}, \mu_{t}, K_{t}\right\}$. 


\subsection{Constructing competitive equilibria}

To study the dynamics of this economy, we define $k_{t}$ as the capital stock in efficiency units, i.e., $k_{t} \equiv \gamma^{-t} \cdot K_{t}$. Also, we define $b_{t}, n_{t}$, and $m_{t}$ as the value of bubbles and money as a share of aggregate wages, i.e., $b_{t} \equiv \frac{B_{t}}{W_{t}}, n_{t} \equiv \frac{N_{t}}{W_{t}}$, and $m_{t} \equiv \frac{M_{t}}{W_{t}}$. By using these de-trended variables, we make the system stationary.

A useful property of this model is that we can construct competitive equilibria recursively. Substituting Equations (2)-(3) and (14)-(15) into Equations (6)-(7), we obtain the following system of equations:

$$
b_{t}+n_{t}\left\{\begin{array}{lr}
=\left[1-m_{t}-b_{t}+\phi \cdot\left(\varepsilon+n_{t}\right)\right] \cdot \frac{1-\alpha}{\alpha} \cdot E_{t} b_{t+1} & \text { if } \frac{m_{t}+b_{t}}{1-\varepsilon-n_{t}}<1, \\
\in\left[\left(\varepsilon+n_{t}\right) \cdot \frac{1-\alpha}{\alpha} \cdot E_{t} b_{t+1},(1+\phi) \cdot\left(\varepsilon+n_{t}\right) \cdot \frac{1-\alpha}{\alpha} \cdot E_{t} b_{t+1}\right] & \text { if } \frac{m_{t}+b_{t}}{1-\varepsilon-n_{t}}=1, \\
=\left(1-m_{t}-b_{t}\right) \cdot \frac{1-\alpha}{\alpha} \cdot E_{t} b_{t+1} & \text { if } \frac{m_{t}+b_{t}}{1-\varepsilon-n_{t}}>1, \\
m_{t}=\lim _{v \rightarrow 0} \max \left\{v, m_{t}^{*}\right\}, &
\end{array}\right.
$$

where $m_{t}^{*}$ is given as follows:

$$
m_{t}^{*} \begin{cases}=\left[1-m_{t}^{*}-b_{t}+\phi \cdot\left(\varepsilon+n_{t}\right)\right] \cdot \frac{1-\alpha}{\alpha} \cdot E_{t}\left\{\frac{m_{t+1}}{\mu_{t+1}}\right\} & \text { if } \frac{m_{t}^{*}+b_{t}}{1-\varepsilon-n_{t}}<1, \\ \in\left[\left(\varepsilon+n_{t}\right) \cdot \frac{1-\alpha}{\alpha} \cdot E_{t}\left\{\frac{m_{t+1}}{\mu_{t+1}}\right\},(1+\phi) \cdot\left(\varepsilon+n_{t}\right) \cdot \frac{1-\alpha}{\alpha} \cdot E_{t}\left\{\frac{m_{t+1}}{\mu_{t+1}}\right\}\right] & \text { if } \frac{m_{t}^{*}+b_{t}}{1-\varepsilon-n_{t}}=1, \\ =\left(1-m_{t}^{*}-b_{t}\right) \cdot \frac{1-\alpha}{\alpha} \cdot E_{t}\left\{\frac{m_{t+1}}{\mu_{t+1}}\right\} & \text { if } \frac{m_{t}^{*}+b_{t}}{1-\varepsilon-n_{t}}>1 .\end{cases}
$$

Note that, from now on, we focus on the limiting case in which $v \rightarrow 0$. When money balances are only held by money holders, we will abuse language and say that $m_{t}=0$, even though it should be understood that the real value of money in our setting is always positive.

The key observation is that the capital stock is not present in Equations (16)-(18) and, as a result, the model has a recursive structure. Any non-negative sequence $\left\{b_{t}, n_{t}, m_{t}, \mu_{t}\right\}$ such that $m_{t}+b_{t}<1$ and $\mu_{t} \geq 1$ is part of a competitive equilibrium if it satisfies Equations (16)-(18) for all $t$ and $h^{t}{ }^{6}$ Let $\mathcal{E}$ be the set that contains all such sequences. The first step to construct a competitive equilibrium is to pick a sequence from this set.

The second step is to determine the implications of the chosen sequence for the capital stock and consumption. It follows from Equations (2) and (14) that:

$$
\begin{aligned}
k_{t+1} & =\min \left\{\frac{1-m_{t}-b_{t}+\phi \cdot\left(\varepsilon+n_{t}\right)}{1+\phi}, 1-m_{t}-b_{t}\right\} \cdot \frac{1-\alpha}{\gamma} \cdot k_{t}^{\alpha}, \\
c_{t} & =\left[\alpha+\left(m_{t}+b_{t}\right) \cdot(1-\alpha)\right] \cdot k_{t}^{\alpha},
\end{aligned}
$$

where $c_{t} \equiv \gamma^{-t} \cdot C_{t}$ and $C_{t}$ is the average consumption at time $t .{ }^{7}$ For any sequence $\left\{b_{t}, n_{t}, m_{t}, \mu_{t}\right\}$, Equations (19)-(20) describe the evolution of the capital stock and consumption from any initial condition $k_{0}>0$.

6. The condition $m_{t}+b_{t}<1$ is equivalent to $k_{t+1}>0$.

7. Formally, $C_{t}=R_{t}^{K} \cdot K_{t}+M_{t}+B_{t}$, since the old finance their consumption with their capital income, plus the proceeds of selling their (old plus new) money, and their (old) bubbles. 
Unbacked assets have two key effects, as shown by Equations (19)-(20). The first one is an intragenerational transfer equal to the supply of new bubbles that young entrepreneurs sell to young savers, i.e., $n_{t}$. This "wealth" effect of bubble creation transfers resources from savers to entrepreneurs, raising the capital stock. Note that money creation also has a wealth effect that transfers resources to the central bank in the form of seigniorage: given our assumption on the distribution of seigniorage to the old, however, it does not affect capital accumulation. The second effect is an intergenerational transfer equal to the supply of money and old bubbles that the old sell to young savers, i.e., $m_{t}+b_{t}$. This "overhang" effect is the same for money and bubbles, and-by transferring resources from savers to the old-it raises consumption by reducing the capital stock. Most of the analysis that follows can be understood in terms of these two transfers or effects. Their relative strength determines whether unbacked assets have an expansionary or a contractionary effect on capital accumulation.

\section{MONETARY POLICY: GENERAL CONSIDERATIONS}

We know now how to construct competitive equilibria and evaluate them. For each sequence $\left\{b_{t}, n_{t}, m_{t}, \mu_{t}\right\} \in \mathcal{E}$, Equation (19) generates a unique path for $k_{t}$ from any initial condition $k_{0}>0$. Thus, we refer somewhat loosely to $\mathcal{E}$ as the set of all equilibria. The next steps are to characterize this set, and then choose equilibria within it.

\subsection{The bubbly world}

The set $\mathcal{E}$ contains all sequences $\left\{b_{t}, n_{t}, m_{t}, \mu_{t}\right\}$ that are part of a competitive equilibrium. Sequences such that $\left\{b_{t}, n_{t}, m_{t}, \mu_{t}\right\}=\left\{0,0,0, \mu_{t}\right\}$ for all $t$ and $h^{t}$ describe equilibria in which there is no demand for unbacked assets. All other sequences describe equilibria in which there are some histories with a positive demand for unbacked assets in some periods. We say that this demand is extreme if the economy is in the second or third regimes described in Section 2.2. Recall that in these regimes only bubbles are traded in the financial market. If the demand for unbacked assets is not extreme, the economy is in the first regime of Section 2.2. Here, both backed debts and bubbles are traded simultaneously in the financial market.

The following proposition provides a characterization of the set $\mathcal{E}$ in terms of these regimes.

Proposition $1 \mathcal{E}$ always contains sequences such that $\left\{b_{t}, n_{t}, m_{t}, \mu_{t}\right\}=\left\{0,0,0, \mu_{t}\right\}$ for all $t$ and $h^{t}$.

1. Non-bubbly world. If $\frac{\alpha}{1-\alpha}>\max \left\{1+\phi \cdot \varepsilon, \frac{1}{4} \cdot \frac{1+\phi}{1-\varepsilon}\right\}$, then $\mathcal{E}$ contains no additional sequences.

2. Bubbly world. If $\frac{\alpha}{1-\alpha}<\max \left\{1+\phi \cdot \varepsilon, \frac{1}{4} \cdot \frac{1+\phi}{1-\varepsilon}\right\}$, then $\mathcal{E}$ also contains sequences with a positive demand for unbacked assets. Moreover,

(i) if $(1+\phi) \cdot \varepsilon<\frac{\alpha}{1-\alpha}$, then $\mathcal{E}$ contains no sequences with an extreme demand for unbacked assets;

(ii) if $(1+\phi) \cdot \varepsilon>\frac{\alpha}{1-\alpha}$, then $\mathcal{E}$ also contains sequences with an extreme demand for unbacked assets. $^{8}$

8. All formal proofs can be found in the Appendix. Throughout, we ignore the non-generic parameter cases where $\frac{\alpha}{1-\alpha}=\max \left\{1+\phi \cdot \varepsilon, \frac{1}{4} \cdot \frac{1+\phi}{1-\varepsilon}\right\}$ or $(1+\phi) \cdot \varepsilon=\frac{\alpha}{1-\alpha}$. 
Our proof of this result proceeds as follows. First, showing that the set $\mathcal{E}$ contains a sequence $\left\{b_{t}, n_{t}, m_{t}, \mu_{t}\right\}=\left\{0,0,0, \mu_{t}\right\}$ for some $\left\{\mu_{t}\right\}$ is straightforward. Second, we characterize the "most sustainable" sequence $\left\{b_{t}, n_{t}, m_{t}, \mu_{t}\right\} \in \mathcal{E}$ where $b_{t}>0$ and/or $n_{t}>0$ and/or $m_{t}>0$ for some $t$ and $h^{t}$. If this sequence implies an explosive path for either bubbles or money, there cannot be another sequence with the property that $b_{t}>0$ and/or $n_{t}>0$ and/or $m_{t}>0$ for some $t$ and $h^{t}$ that is nonexplosive. ${ }^{9}$ We show that the condition $\frac{\alpha}{1-\alpha}>\max \left\{1+\phi \cdot \varepsilon, \frac{1}{4} \cdot \frac{1+\phi}{1-\varepsilon}\right\}$ is necessary and sufficient for this most sustainable sequence to be explosive. Instead, the condition $(1+\phi) \cdot \varepsilon>\frac{\alpha}{1-\alpha}$ is necessary and sufficient for it to be explosive if the equilibrium is ever outside of the first regime described in Section 2.2.

Figure 1 provides a graphical illustration of Proposition 1. The demand for unbacked assets is positive whenever the return to backed debts is low enough. This depends on the values of $\alpha$ and $\phi .{ }^{10}$ A low value of $\alpha$ reduces the marginal product of capital. A high value of $\phi$ reduces the share of this marginal product that can be appropriated by the savers. Both depress the return to backed debts and create the conditions for unbacked assets to have positive values. The unshaded region at the top of the figure depicts the non-bubbly world, where the return to backed debts is high, and there is thus no demand for unbacked assets. Instead, the other two regions depict the bubbly world, where the return to backed debts is low, and there is thus a potential demand for unbacked assets. This demand is not extreme in the shaded region of the figure, but it is extreme in the unshaded region.

In the non-bubbly world, the capital stock and consumption are given by:

$$
\begin{aligned}
k_{t+1} & =\frac{1+\phi \cdot \varepsilon}{1+\phi} \cdot \frac{1-\alpha}{\gamma} \cdot k_{t}^{\alpha}, \\
c_{t} & =\alpha \cdot k_{t}^{\alpha} .
\end{aligned}
$$

Thus, from any initial condition, $k_{0}>0$, these variables monotonically and deterministically converge to:

$$
\begin{aligned}
& k_{\infty}=\left(\frac{1+\phi \cdot \varepsilon}{1+\phi} \cdot \frac{1-\alpha}{\gamma}\right)^{\frac{1}{1-\alpha}} \\
& c_{\infty}=\alpha \cdot\left(\frac{1+\phi \cdot \varepsilon}{1+\phi} \cdot \frac{1-\alpha}{\gamma}\right)^{\frac{\alpha}{1-\alpha}}
\end{aligned}
$$

The economy exhibits standard growth dynamics without asset price shocks.

The non-bubbly world is very quiet and monetary policy makes no difference. We shall not analyse it further. Instead, we focus on the bubbly world from now on. To streamline the discussion, we also restrict our analysis to the shaded parameter region of Figure 1 . That is, we focus on the case in which the demand for unbacked assets is never extreme and the economy always remains in the first regime described in Section 2.2. Though a full analysis of the bubbly world that includes the parameter region with an extreme demand for unbacked assets is also possible, it is cumbersome and adds few additional insights.

9. The process for $b_{t}$ or $m_{t}$ is explosive if $m_{t}+b_{t} \geq 1$ with positive probability in finite time.

10. This discussion keeps $\varepsilon<\frac{1}{2}$ fixed in the background. Since $1-\varepsilon$ is the share of savings that need to be intermediated, the effect of an increase in $\varepsilon$ is similar to that of an increase in $\phi$. 




FIGURE 1

This figure illustrates combinations of $\alpha$ and $\phi$ such that: there is no demand for unbacked assets (top-unshaded region); there is potential demand for unbacked assets that is not extreme (shaded region); and there is potential demand for unbacked assets that is extreme (bottom-unshaded region).

\subsection{A model of market psychology}

The bubbly world is characterized by multiple equilibria, each of which corresponds to a different sequence $\left\{b_{t}, n_{t}, m_{t}, \mu_{t}\right\} \in \mathcal{E}$. To select among them, we introduce now the concept of market psychology. Formally, we define a market psychology $\mathcal{P}$ as a rule to produce a subset $\mathcal{E}^{\mathcal{P}} \subseteq \mathcal{E}$, i.e., a selection rule that discards equilibria that are not in $\mathcal{E}^{\mathcal{P}}$. We say that a market psychology $\mathcal{P}$ is feasible if $\mathcal{E}^{\mathcal{P}}$ is non-empty.

Next, we define $\mathcal{M}$ to denote a monetary policy rule, i.e., a sequence $\left\{\mu_{t}\right\}$ such that $\mu_{t} \geq 1$ for all $t$ and $h^{t}$. Given a market psychology $\mathcal{P}$, we let $\mathcal{E}^{\mathcal{M}, \mathcal{P}} \subseteq \mathcal{E}^{\mathcal{P}}$ be the subset of $\mathcal{E}^{\mathcal{P}}$ containing all equilibria that are consistent with $\mathcal{M}$. We say that $\mathcal{M}$ is feasible if $\mathcal{E}^{\mathcal{M}, \mathcal{P}}$ is not empty. We say that $\mathcal{M}$ is decisive if $\mathcal{E}^{\mathcal{M}, \mathcal{P}}$ is a singleton. That is, given a market psychology, a decisive monetary policy rule selects one equilibrium only. Instead, a monetary policy that is feasible but not decisive selects two or more equilibria.

This procedure to select equilibria could be interpreted as a sequential game between nature and the central bank. Nature "moves first" and picks a market psychology $\mathcal{P}$. The central bank "moves second" and picks a monetary policy $\mathcal{M}$ that is feasible given this market psychology. In this section, we propose a specific class of market psychologies and, in the next section, we search for an optimal monetary policy rule conditional on this class of market psychologies. Thus, we are essentially adopting the role of a central banker who is designing monetary policy with a limited ability to influence market sentiment. 
We focus on a class of market psychologies defined in terms of an initial condition $b_{0}$ and two types of shocks: (i) bubble return shocks: $u_{t+1} \equiv \frac{b_{t+1}}{E_{t} b_{t+1}} \geq 0$; and (ii) bubble-creation shocks: $n_{t} \geq 0$. Let $\mathcal{S}=\left\{\left(u_{1}, n_{1}\right),\left(u_{2}, n_{2}\right), \ldots,\left(u_{S}, n_{S}\right)\right\}$ be a finite state space for these shocks and let $\mathcal{T}$ be an $S \times S$ matrix of constant transition probabilities. To simplify some arguments that follow, we assume that $\mathcal{T}$ has no zeros. We define the following class of market psychologies:

$$
\mathcal{P}(\beta, \mathcal{S}, \mathcal{T}) \equiv\left\{b_{0}=\beta \text { and }\left\{u_{t}, n_{t}\right\} \text { is a Markov chain on } \mathcal{S} \text { with transition matrix } \mathcal{T}\right\}
$$

That is, we index market psychologies by $\beta, \mathcal{S}$, and $\mathcal{T}$. This family turns out to be very useful analytically. Moreover, it is quite intuitive from an economic point of view: bubble-return shocks capture the notion that there are random movements in the value of old bubbles, whereas bubblecreation shocks capture the notion that the value of new bubbles is also random.

Naturally, a market psychology has to be feasible. In the non-bubbly world, for instance, the only feasible market psychology within this family is the trivial one with $\beta=0, \mathcal{S}=\{(0,0)\}$. We next characterize the set of feasible market psychologies in the bubbly world.

Proposition 2 The market psychology $\mathcal{P}(\beta, \mathcal{S}, \mathcal{T})$ is feasible if and only if:

1. For all $\left\{u_{s}, n_{s}\right\} \in \mathcal{S}$ :

$$
\Gamma_{s} \equiv\left[1+\phi \cdot\left(\varepsilon+n_{s}\right)-\frac{\alpha}{1-\alpha} \cdot u_{s}\right]^{2}-4 \cdot \frac{\alpha}{1-\alpha} \cdot u_{s} \cdot n_{s} \geq 0 .
$$

2. $b_{H} \equiv \min _{s \in \mathcal{S}} b_{H, s} \geq \max _{s \in \mathcal{S}} b_{L, s} \equiv b_{L}$, where $b_{H, s}$ and $b_{L, s}$ are defined as follows:

$$
\begin{aligned}
& b_{H, s} \equiv \frac{1}{2} \cdot\left[1+\phi \cdot\left(\varepsilon+n_{s}\right)-\frac{\alpha}{1-\alpha} \cdot u_{s}+\sqrt{\Gamma_{s}}\right], \\
& b_{L, s} \equiv \frac{1}{2} \cdot\left[1+\phi \cdot\left(\varepsilon+n_{s}\right)-\frac{\alpha}{1-\alpha} \cdot u_{s}-\sqrt{\Gamma_{s}}\right] .
\end{aligned}
$$

3. $\beta \leq b_{H}$.

Our proof of this result proceeds as follows. First, we show that if $\mathcal{P}$ is feasible and $\mathcal{E}^{\mathcal{P}}$ contains sequences with $m_{t}>0$ for some $t$ and $h^{t}$, then it must also contain sequences with $m_{t}=0$ for all $t$ and $h^{t}$. Intuitively, money raises the interest rate and makes the set of feasible bubbles smaller. Second, we compute the set of feasible market psychologies as the set of non-explosive solutions to Equation (16) with $m_{t}=0$ for all $t$ and $h^{t}$. This places an upper bound on the initial size of the bubble and it also limits the extent to which the bubble can vary across states and, therefore, histories. The first part of the proposition provides the conditions under which the bubble process is non-explosive conditional on remaining in any given state forever. The second part guarantees that there is a bubble process that is non-explosive even if there are transitions across states. Finally, the third part states that the initial bubble must be small enough; otherwise, it will be on an explosive path with positive probability.

\section{WHAT SHOULD THE CENTRAL BANK DO?}

We have shown how to construct market psychologies that are feasible. We next use this flexible model of market psychology to study the conduct of monetary policy. 


\subsection{Passive and optimal policies}

Given a feasible market psychology $\mathcal{P}$, a feasible monetary policy is given by a rule $\mathcal{M}$ such that the set $\mathcal{E}^{\mathcal{M}, \mathcal{P}}$ is non-empty. Recall that this set consists of all non-explosive sequences $\left\{b_{t}, n_{t}, m_{t}, \mu_{t}\right\}$ satisfying the following equations:

$$
\begin{aligned}
& b_{t}+n_{t}=\left[1-m_{t}-b_{t}+\phi \cdot\left(\varepsilon+n_{t}\right)\right] \cdot \frac{1-\alpha}{\alpha} \cdot E_{t} b_{t+1}, \\
& m_{t}=\left[1-m_{t}-b_{t}+\phi \cdot\left(\varepsilon+n_{t}\right)\right] \cdot \frac{1-\alpha}{\alpha} \cdot E_{t}\left\{\frac{m_{t+1}}{\mu_{t+1}}\right\},
\end{aligned}
$$

which are the same as Equations (16)-(18), since we have assumed that the economy is in the first regime of Section 2.2 where the demand for unbacked assets is never extreme.

Through its choice of sequence $\left\{\mu_{t}\right\}$, monetary policy affects the evolution of the supply of unbacked assets $\left\{b_{t}, m_{t}\right\}$; recall that $n_{t}$ is driven by market psychology. Moreover, it is only through its effect on the total supply of unbacked assets, which we denote by $\left\{x_{t}\right\} \equiv\left\{b_{t}+m_{t}\right\}$, that monetary policy affects the capital stock and consumption:

$$
\begin{aligned}
k_{t+1} & =\frac{1-x_{t}+\phi \cdot\left(\varepsilon+n_{t}\right)}{1+\phi} \cdot \frac{1-\alpha}{\gamma} \cdot k_{t}^{\alpha}, \\
c_{t} & =\left[\alpha+x_{t} \cdot(1-\alpha)\right] \cdot k_{t}^{\alpha},
\end{aligned}
$$

which are the same as Equations (19)-(20) since we are in the first regime.

The following proposition shows that monetary policy can always take the economy outside of the liquidity trap.

Proposition 3 Given any feasible market psychology $\mathcal{P}$, there exists a feasible and decisive monetary policy rule $\mathcal{M}$ such that in equilibrium $m_{t}=0$ for all $t$ and $h^{t}$.

Intuitively, it is always possible to set the money growth rate $\mu_{t}$ sufficiently high for all $t$ and $h^{t}$, ensuring high enough inflation so that money never becomes attractive as a store of value. When this is the case, we say that monetary policy is passive. A passive monetary policy may not be optimal, though.

We adopt a generational perspective of optimality and focus on the implications of monetary policy for the evolution of average consumption (or, equivalently, welfare) $c_{t}$. In doing so, we abstract from issues of intra-generational redistribution. Given a feasible market psychology $\mathcal{P}$, we say that a monetary policy rule $\mathcal{M}$ is optimal if (i) it is feasible and decisive and (ii) there does not exist another feasible monetary policy rule $\mathcal{M}^{\prime}$ that increases the consumption of any one generation without decreasing the consumption of some other generation.

The following proposition states our main result.

Proposition 4 Given a market psychology $\mathcal{P}$, there exists a feasible and decisive monetary policy rule $\mathcal{M}$ such that the (stationary) equilibrium supply of unbacked assets is:

$$
x_{\mathcal{P}}^{*}= \begin{cases}b_{L} & \text { if } \max _{s \in \mathcal{S}} \Omega\left(n_{S}\right) \leq b_{L} \\ \max _{s \in \mathcal{S}} \Omega\left(n_{s}\right) & \text { if } b_{L}<\max _{s \in \mathcal{S}} \Omega\left(n_{S}\right) \leq b_{H}, \\ b_{H} & \text { if } b_{H}<\max _{s \in \mathcal{S}} \Omega\left(n_{s}\right)\end{cases}
$$

where $\Omega\left(n_{s}\right) \equiv 1+\phi \cdot\left(\varepsilon+n_{S}\right) \cdot(1-\alpha)-\frac{\alpha}{1-\alpha}$. Moreover, the monetary policy rule $\mathcal{M}$ is optimal. 




FIGURE 2

This figure illustrates the law of motion of the bubble under deterministic market psychology and passive monetary policy.

Proposition 4 identifies a specific optimal monetary policy rule, which completely stabilizes the supply of unbacked assets even in the face of fluctuations in market psychology. We now demonstrate the macroeconomic effects of this rule and provide an intuition for its optimality and implementation by considering a series of examples.

\subsection{Deterministic bubbles}

Consider first the case of a "deterministic" market psychology that does not generate fluctuations in the supply of unbacked assets. In particular, we assume that $\mathcal{S}$ is a singleton, and $u_{t}=1$ and $n_{t}=\eta>0$ for all $t$ and $h^{t}$. In the discussion that follows, we ignore transitional dynamics and focus on stationary equilibria, in which the bubble has already converged to its stationary or steady state value.

Figure 2 depicts the law of motion of the bubble (as given by Equation (28)) under a passive monetary policy. It is immediate that, for any initial bubble $\beta<b_{H}$, the bubble converges monotonically to its steady state value $b_{L}$, where the values for $b_{H}$ and $b_{L}$ are defined in Proposition $2 .{ }^{11}$ The paths starting from any initial bubble above $b_{H}$ are in turn explosive. Thus, ignoring the non-generic case where the initial bubble is exactly equal to $b_{H}$, it follows that under a passive monetary policy the equilibrium supply of unbacked assets equals $b_{L}$, and the capital stock and

11. It can be readily verified that this market psychology is feasible as long as $\eta$ is not too large. 


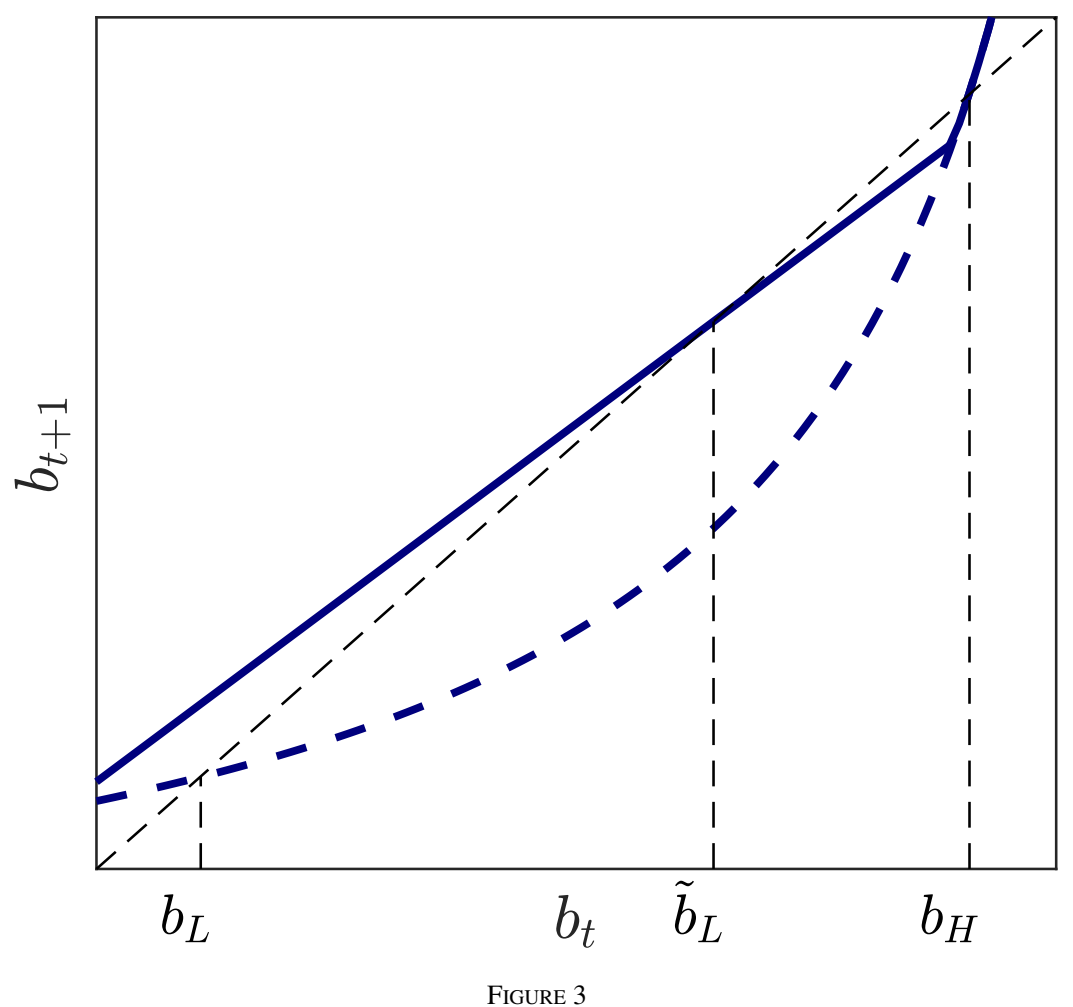

This figure illustrates the law of motion of the bubble under deterministic market psychology and passive monetary policy (dashed curve) versus optimal monetary policy (solid curve).

consumption are respectively given by:

$$
\begin{aligned}
& k^{\text {pass }}=\left(\frac{1-b_{L}+\phi \cdot(\varepsilon+\eta)}{1+\phi} \cdot \frac{1-\alpha}{\gamma}\right)^{\frac{1}{1-\alpha}}, \\
& c^{\text {pass }}=\left[\alpha+b_{L} \cdot(1-\alpha)\right] \cdot\left(k^{\text {pass }}\right)^{\alpha} .
\end{aligned}
$$

As we had already anticipated, this policy may not be optimal. The intuition for this is well known in overlapping generations economies: absent unbacked assets, investment may be inefficiently high. Optimality requires that the supply of unbacked assets be large enough to eliminate dynamically inefficient investments. In our economy, the extent of dynamic inefficiency depends both on the financial friction, as captured by $\phi$, and on the market psychology, as captured by $\eta$. A more severe financial friction (higher $\phi$ ) reduces the return to intermediated investment and raises the demand for unbacked assets. A larger wealth effect of bubbles (higher $\eta$ ) raises the capital stock and reduces the return to investment, thereby also increasing the demand for unbacked assets.

The target $\Omega(\eta)$ defined in Proposition 4 is the minimum supply of unbacked assets that is required to eliminate inefficient investments. Whether this target is attainable or not depends on market psychology, which determines both $b_{L}$ and $b_{H}$, i.e., the lower- and upper-bound to the supply of unbacked assets that are consistent with equilibrium. This supply can never fall below $b_{L}$, as the central bank can only add to- but not subtract from-the unbacked assets supplied by 
Capital

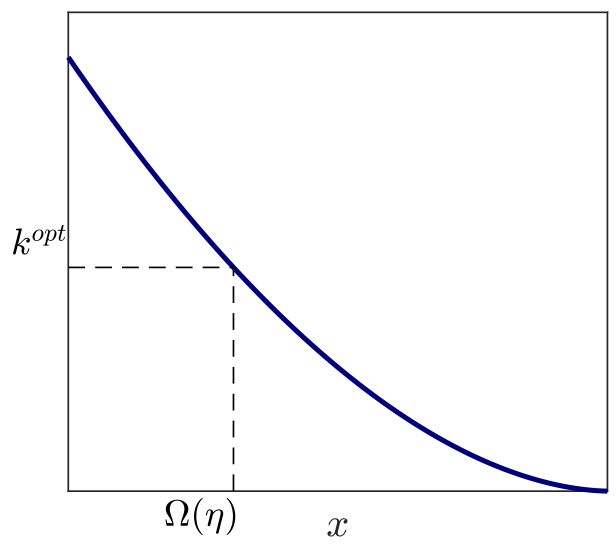

Consumption

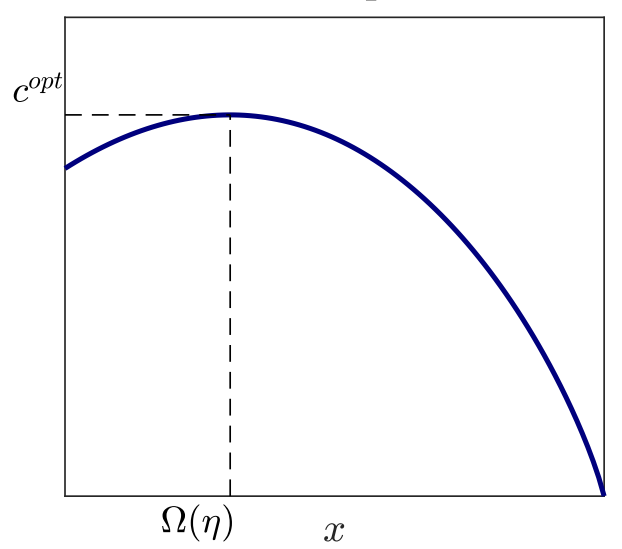

FIGURE 4

This figure illustrates the effect of the supply of unbacked assets on the steady state values for the capital stock and consumption.

the bubble. But the supply of unbacked assets cannot exceed $b_{H}$ either, because doing so would put the bubble on an explosive path.

Figure 3 depicts the law of motion of the bubble under the passive monetary policy (dashed curve) and the optimal policy rule (solid curve) of Proposition 4, in the case when $b_{L}<\Omega(\eta)<b_{H}$, so that $x_{\mathcal{P}}^{*}=\Omega(\eta)$. In this scenario, the private supply of unbacked assets is too small and the optimal policy rule requires that the central bank complement it by providing additional stores of value in the form of real balances. By doing so, the central bank raises the equilibrium interest rate, which is captured in the figure by an upward shift in the law of motion of the bubble. Moreover, by raising equilibrium interest rates, the optimal policy accelerates the growth of the bubble and raises its stationary value to $\widetilde{b}_{L}>b_{L}{ }^{12}$

By altering the equilibrium supply of unbacked assets, the optimal monetary policy rule affects the capital stock and consumption, which are now:

$$
\begin{aligned}
& k^{\mathrm{opt}}=\left[\frac{1-x_{\mathcal{P}}^{*}+\phi \cdot(\varepsilon+\eta)}{1+\phi} \cdot \frac{1-\alpha}{\gamma}\right]^{\frac{1}{1-\alpha}}, \\
& c^{\mathrm{opt}}=\left[\alpha+x_{\mathcal{P}}^{*} \cdot(1-\alpha)\right] \cdot\left(k^{\mathrm{opt}}\right)^{\alpha} .
\end{aligned}
$$

As we had already anticipated, an increase in the supply of stores of value reduces the capital stock because it eliminates some investment. To the extent that this displaced investment is inefficient, consumption actually increases. In fact, given our definition of $\Omega(\eta)$, any increase in the supply of stores of value up to $\Omega(\eta)$ is guaranteed to raise steady-state consumption. Targeting an asset supply beyond this level is also optimal because it eliminates all inefficient investments. But doing so may reduce steady-state consumption by eliminating some efficient investment as well! Under a deterministic market psychology, therefore, the monetary policy rule described in

12. Though we ignore transitional dynamics, these are straightforward. For instance, if the bubble starts below $\widetilde{b}_{L}$, then the central bank temporarily places the economy in a liquidity trap, sets $m_{t}=x_{\mathcal{P}}^{*}-b_{t}$, and gradually reduces real money balances as the bubble converges to $\widetilde{b}_{L}$. If the bubble starts above $\widetilde{b}_{L}$, then the central bank sets $m_{t}=0$ until the bubble reaches $x_{\mathcal{P}}^{*}$. 
Proposition 4 has the additional attractive feature of maximizing steady-state consumption, as depicted in Figure 4.

What changes when $\Omega(\eta) \notin\left(b_{L}, b_{H}\right)$ ? In this case, the optimal policy is constrained by the market psychology and it is unable to implement the supply of assets that maximizes consumption. When $\Omega(\eta) \leq b_{L}$, the market psychology implies that the equilibrium supply of assets is necessarily higher than $\Omega(\eta)$ : thus, the optimal policy does not alter the supply of assets and has no effect on the capital stock or consumption. When $b_{H} \leq \Omega(\eta)$, the market psychology implies that the equilibrium supply of assets can be no higher than $b_{H}$, since otherwise the bubble would be explosive. Thus, the optimal policy increases the equilibrium supply of assets as much as possible, i.e., to $b_{H}$, but it is unable to attain the level that would maximize consumption.

Finally, as for implementation, the central bank can guarantee that the equilibrium supply of unbacked assets is $x_{\mathcal{P}}^{*}$ by simply setting the money growth rate to:

$$
\mu^{*}=\frac{1-\alpha}{\alpha} \cdot\left[1+\phi \cdot(\varepsilon+\eta)-x_{\mathcal{P}}^{*}\right]
$$

which is shown to pin down the value of money balances uniquely; in this sense, the monetary policy rule is decisive. ${ }^{13}$ Intuitively, in order to increase the supply of stores of value, the central bank must decrease money growth and thus inflation, so as to make money more attractive.

\subsection{Stochastic bubbles}

We now turn to "stochastic" market psychologies that may generate bubbly business cycles. We again ignore transitional dynamics and focus on stationary equilibria, in which the bubble has already converged to its stationary or steady state distribution.

To fix ideas, we consider a simple market psychology that gives rise to "bubbly episodes." In particular, suppose that the state-space is $\mathcal{S}=\{F, B\}$ and the economy fluctuates between a fundamental state $s=F$, in which $n_{F}=0$ and $u_{F}=0$, and a bubbly state $s=B$, in which $n_{B}=\eta>0$ and $u_{B}>1$. Let $\tau_{s s^{\prime}}$ denote the transition probability from state $s$ to $s^{\prime}$, then it must be that $u_{B} \cdot \tau_{B B}=1$, so that the evolution of the bubble satisfies Equation (28). ${ }^{14}$ Thus, whenever the economy is in the bubbly state, there is a probability $\tau_{B F}$ that it transitions to the fundamental state, in which case $u_{t+1}=0$ and the bubble bursts fully. Conversely, there is a probability $\tau_{B B}$ that the economy continues in the bubbly state, in which case $u_{t+1}>1$ and the realized return to the bubble is higher than the market interest rate.

In this example, the law of motion of the bubble fluctuates with the state of the economy. Consider first the passive monetary policy rule that sets $m_{t}=0$ for all $t$ and $h^{t}$. In the fundamental state, the law of motion of the bubble is simply $b_{t+1}=0$. In the bubbly state, the law of motion is instead qualitatively similar to the one depicted in Figure $2 .{ }^{15}$ It is immediate that, for any initial bubble $\beta<b_{H}$, the bubble gradually converges to the interval $\left[0, b_{L}\right]$ and, once there, it oscillates

13. Our proof of decisiveness relies on showing that, if the central bank set the money growth rate to $\mu^{*}$ but the supply of unbacked assets exceeded $x_{\mathcal{P}}^{*}$ in any period, then it would be explosive thereby contradicting the notion of equilibrium. On the other hand, if the supply of unbacked assets fell short of $x_{\mathcal{P}}^{*}$ in any period, then the value of money would eventually collapse below the arbitrarily small but positive demand of money holders, which cannot be part of competitive equilibrium either. In this sense, the role of money holders in our setting is akin to that of fundamental backing of money in Obstfeld and Rogoff (1983), who show that (even if arbitrarily small) such backing can rule out hyper-inflationary paths in which the value of fiat money goes to zero.

14. It can be readily verified that this market psychology is feasible provided that $\eta$ and $u_{B}$ are not too large.

15. The only difference is that, because $u_{t+1}>1$, the law of motion of the bubble is shifted up and increases faster than the deterministic one; as a result, now $b_{L}$ is larger and $b_{H}$ is smaller. 
Bubble



Capital



Money

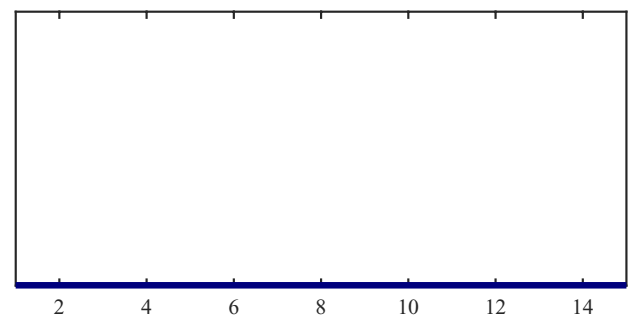

Consumption



FIGURE 5

This figure illustrates the equilibrium dynamics of the economy under stochastic market psychology and passive monetary policy.

permanently within this interval. As long as the economy is in the bubbly state, the bubble grows towards $b_{L}$; when the economy transitions to the fundamental state, however, the bubble collapses to zero and stays there until the next bubbly episode begins. Therefore, ignoring the non-generic case where the initial bubble is exactly equal to $b_{H}$, the supply of unbacked assets in this economy fluctuates in the interval $\left[0, b_{L}\right]$, and the capital stock and consumption are given by Equations (30) and (31), respectively, with $x_{t}=b_{t}$.

Figure 5 illustrates the fluctuations in the capital stock and consumption under passive monetary policy by simulating a particular realization of the market psychology. The economy begins in the fundamental state with $b_{t}=0$ (top-left panel). After a few periods, it transitions to the bubbly state, during which both bubble creation and high bubble returns fuel the growth of the bubble. In this simulation, the wealth effect of bubble creation dominates the overhang effect of bubble returns and therefore investment, output, and consumption all expand for as long as the economy remains in the bubbly state. Eventually, however, all these effects operate in reverse when the economy transitions back to the fundamental state and the bubble bursts.

This example illustrates that, when monetary policy is passive, the supply of assets $x_{t}$ follows the whims of market psychology. This need not be desirable. To see this, we now turn to the optimal policy of Proposition 4.

Figure 6 depicts the evolution of the same variables as in Figure 5, under both the passive monetary policy (solid lines) and the optimal policy rule (dashed lines). The figure assumes that $b_{L}<\Omega(\eta)<b_{H}$, so that the optimal policy sets $x_{\mathcal{P}}^{*}=\Omega(\eta)$. In this case, the private supply of unbacked assets is too small in both states, and the optimal policy rule requires the central bank to always supply additional real balances. This supply now fluctuates with the bubble, rising when the bubble collapses and falling when the bubble grows. The economy begins in the fundamental state with $b_{t}=0$ and the central bank supplies real balances so that the stock of unbacked assets 


\section{Bubble}

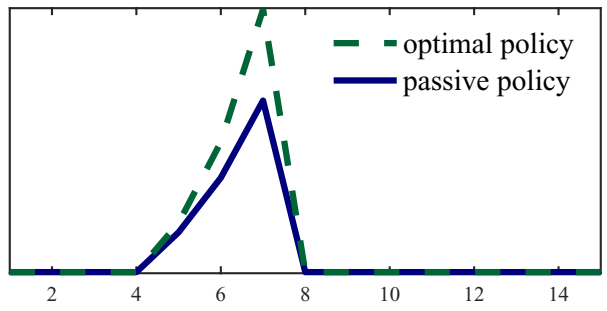

Capital

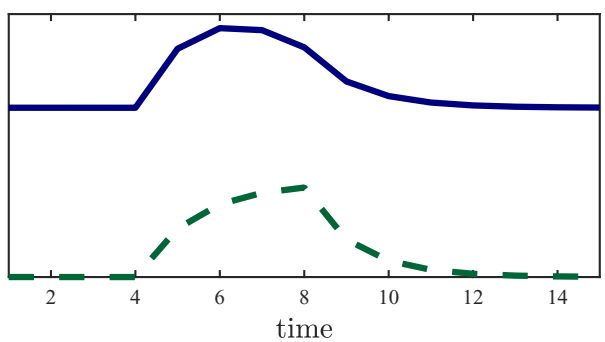

Money



Consumption

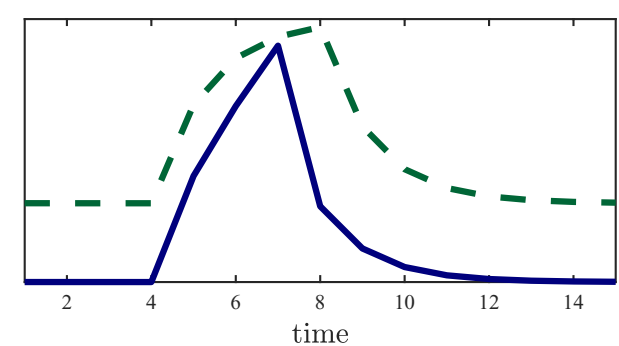

FIGURE 6

This figure illustrates the equilibrium dynamics of the economy under stochastic market psychology and optimal monetary policy.

equals $x_{\mathcal{P}}^{*}$. When the economy transitions to the bubbly state, the bubble grows but real balances are reduced to keep the total stock of unbacked assets unchanged. Since the total supply of unbacked assets is higher under the optimal policy than under the passive policy at all times, the capital stock and output are lower as well. Consumption, however, is always higher! The reason should be clear by now: by adjusting the supply of real balances, the optimal policy eliminates inefficient investments and raises the resources available for consumption.

To conclude, we turn to implementation. In the proof of Proposition 4, we show that the central bank can guarantee that the equilibrium supply of unbacked assets is constant and equal to $x_{\mathcal{P}}^{*}$ with an appropriate choice of sequence $\left\{\mu_{t}^{*}\right\}$. Moreover, in the stationary equilibrium, these money growth rates are given by:

$$
\mu_{t+1}^{*}=\frac{1-\alpha}{\alpha} \cdot\left[1+\phi \cdot\left(\varepsilon+n_{t}\right)-x_{\mathcal{P}}^{*}\right] \cdot \frac{E_{t}\left\{x_{\mathcal{P}}^{*}-b_{t+1}\right\}}{x_{\mathcal{P}}^{*}-b_{t}}
$$

Intuitively, when the bubble grows during the bubbly episode, the central bank raises money growth in order to reduce the supply of stores of value. When the bubble bursts and the private stores of value disappear, the central bank instead reduces money growth in order to make money attractive as a store of value. A crucial feature of the policy, which we discuss further in Section 5, is that $\mu_{t}^{*} \geq 1$ for all $t$ and $h^{t}$, so that the central bank never needs "fiscal resources" to implement its target.

The above market psychology provides the simplest environment in which to analyse the cyclical implications of optimal monetary policy rule. It should be clear, however, the insights it provides extend to market psychologies with richer stochastic structure. 


\subsection{Discussion}

We live in a bubbly world, characterized by low interest rates and large booms and busts in asset prices. How should monetary policy be conducted in this world? How is the bursting of bubbles linked to the emergence of liquidity traps and to the growth of central bank balance sheets? How is the central bank's ability to supply assets affected by the presence of bubbles?

The theory developed here enables us to address these questions. By limiting the supply of backed assets, financial frictions depress the interest rate and open the door for asset bubbles to arise. Bubbles are useful because they provide additional—albeit unbacked—assets. But bubbles are driven by market psychology, so that they may be potentially volatile and their size can be sub-optimal. In such a world, we have shown that there is a novel and powerful role for monetary policy: to complement unbacked assets supplied by the private sector. We have also characterized an optimal policy that fully stabilizes the economy's supply of unbacked assets. In order to implement this policy, the central bank must expand its supply of assets-and thus its balance sheet - when the bubble is small and contract it when the bubble is large. Such a policy raises the welfare of all generations by eliminating inefficient investments.

It is useful to briefly relate our policy analysis to the more conventional interest rate policies, as typically studied in the New Keynesian literature. In our setting, the central bank sets the nominal interest rate by choosing the growth rate of money. If the money growth rate is high enough, the nominal interest rate is positive (i.e. $R_{t+1}>E_{t} \pi_{t+1}^{-1}$ ) so that real balances are dominated by other assets. In this scenario, $m_{t}=0$ and the equilibrium capital stock and consumption become independent of monetary policy (see Equations (19) and (20)), which is therefore neutral. ${ }^{16}$ If the money growth rate is low enough, however, the nominal interest rate is zero (i.e. $\left.R_{t+1}=E_{t} \pi_{t+1}^{-1}\right)$ so that real balances become a perfect substitute of other assets. In this scenario, $m_{t}>0$ and the equilibrium capital stock and consumption depend on the size of money balances. Because different money growth rates correspond to different paths for real balances, the nominal interest rate no longer suffices to pin down equilibrium allocations. Thus, monetary policy in the bubbly world can no longer be summarized in the nominal interest rate: it also requires knowledge of the money growth rates.

Furthermore, the role of the central bank as a supplier of assets is not present in the New Keynesian literature. A natural question is whether this role should indeed be assigned to the central bank or, alternatively, be taken up by the fiscal authority. At first glance, there appears to be a fundamental difference between fiat money and public debt. Unlike money, debt has a well-defined maturity and - at any given point in time—all bonds in circulation will be redeemed at some future date. ${ }^{17}$ This implies that there cannot be a rational bubble on these bonds. To see this, consider a bond that matures at time $T$. It is evident that there cannot be a bubble on the price of this bond at time $T-1$, because whoever purchases it will not resell it in the future. Backward induction then rules out the possibility of a bubble on the price of this bond for $t<T$. Simply put, each bond is "backed" by its redemption at maturity.

The previous argument does not rule out the possibility of a bubble on the fiscal authority itself, however. This happens when the fiscal authority issues debt in excess of the net present value of the taxes that it will collect in the future, i.e., in excess of its fiscal backing. Such "excessive" debt will nonetheless be purchased by rational savers if they expect the fiscal authority to be able

16. That is, although alternative specifications for money growth rates correspond to different paths for inflation and nominal rates, they imply the same path for the capital stock and consumption. This happens in our setting because of the lack of nominal rigidities. Otherwise, we would be in the New Keynesian paradigm and different paths of nominal interest rates would imply different paths for the capital stock and consumption.

17. One exception is the case of consol bonds, which were issued by the U.K. between the late 18th and the early 20th century. 
to issue excessive debt also in the future. In this case, the fiscal authority is expected to roll over part of its debt indefinitely.

In light of this insight, we could reinterpret many of the results of the paper through the lens of fiscal policy. Specifically, a fiscal authority—even without fiscal backing!—could potentially replicate the class of policies analysed here by providing stores of value in the form of public debt. In response to the bursting of the private bubble, for instance, the fiscal authority could expand its supply of assets by issuing more debt; in response to the growth of the private bubble, it could contract the supply of assets by partially defaulting on its debt.

Although theoretically possible, there are at least two reasons that may prevent the fiscal authority from supplying stores of value effectively in practice. The first is that, while the central banks in most countries are autonomous and can respond quickly to changes in the economic environment (e.g. fluctuations in the private bubbles), the fiscal authority is constrained by a political process, and typically reacts slowly and with a lag. Indeed, this is one interpretation of the balance sheet expansions carried out by major central banks in the wake of the global financial crisis: namely, central banks were forced to intervene in the face of an insufficient response of fiscal policy. Ultimately, central banks attempted to expand the supply of stores of value given the scarcity of assets supplied by both, the private sector and the fiscal authority.

The second reason is that it may be easier for the central bank to supply bubbles in the form of real balances than it is for the fiscal authority to supply them in the form of public debt. This is true whenever money is special, e.g., it provides transaction services in a way that public debt does not. ${ }^{18}$ As we have shown, such "specialness" of money allows the central bank to control the value of real balances; a pure bubble on public debt, however, is likely to be governed by market psychology in much the same way as private bubbles, thus limiting its appeal as a store of value. ${ }^{19}$

\section{MONETARY POLICY AND ITS LIMITS}

Thus far, we have stacked the cards against monetary policy, making restrictive assumptions about the functioning of the central bank. In particular, we assumed that (i) the central bank lacks fiscal backing, i.e., its seigniorage must be non-negative; (ii) the central bank distributes seigniorage to the old, i.e., it is unable to transfer or lend these resources to financially constrained entrepreneurs, and; (iii) the central bank cannot influence market psychology. We now discuss the consequences of relaxing these assumptions.

\subsection{Fiscal backing}

If the central bank lacks fiscal backing, the monetary policies it can implement are limited to those having non-negative seigniorage, i.e., satisfying $\mu_{t} \geq 1$ for all $t$ and $h^{t}$. Despite this, we have shown that the central bank can fully stabilize the supply of unbacked assets.

This result may strike the reader as surprising. How is it possible for the central bank to control the value of real balances, and thus of unbacked assets, without having access to real resources? Part of the answer lies in the presence of money holders, who provide an arbitrarily small but stable demand for money. Embedded in a bubbly world, in which there is potential demand for stores of value, the presence of money holders rules out equilibria with hyper-inflationary paths

18. This is captured in our model through the presence of money holders, whose positive demand enables the central bank to anchor the value of real balances.

19. In some countries, such as the U.S., it is argued that public debt has money-like features (Krishnamurthy and Vissing-Jorgensen, 2012), effectively blurring the distinction between the two. 


\section{Unbacked assets}



Money growth

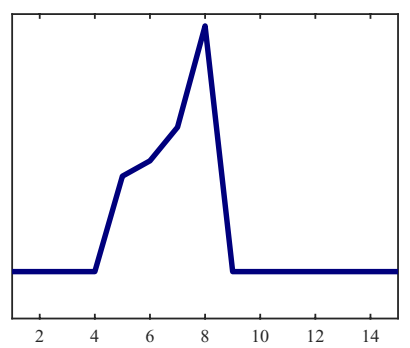

Inflation

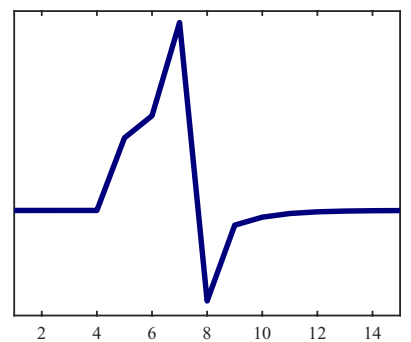

FIGURE 7

This figure illustrates the equilibrium dynamics of unbacked assets, money growth, and the inflation rate under stochastic market psychology and optimal monetary policy.

in which the real value of money collapses to zero. But, more importantly, even if money is guaranteed to have positive value, how can the central bank manage it at will, i.e., increase the value of money when the bubble is small and decrease it when the bubble is large? The answer is inflation.

Figure 7 reproduces the evolution of the economy in Figure 6, but now showing the equilibrium dynamics of unbacked assets, money growth, and the inflation rate. Recall that the policy perfectly stabilizes the supply of unbacked assets; as a result, real balances fall when the bubble grows and rise when the bubble bursts. The figure illustrates that part of this adjustment is attained through fluctuations in inflation, i.e., part of the fall (rise) of real balances is attained through an increase (decrease) of the inflation rate. In our model, this is irrelevant as there are no costs associated to inflation volatility. But in the presence of such costs-due, for instance, to nominal rigidities-such a policy could be costly.

If the central bank has also inflation objectives, then stabilizing the asset supply may require fiscal backing. To see this, consider that the bubble grows today and our policy mandates a reduction in real balances. According to our current policy rule, the central bank can attain this reduction by promising a higher rate of money growth-and thus a higher expected rate of inflation-which reduces the demand for money balances today. If there is a limit to how much inflation can rise, however, it may well be that the only way for the central bank to reduce real balances today is by actually contracting the nominal money supply. But orchestrating such "buybacks" of money clearly requires access to fiscal resources.

\subsection{Distribution of seigniorage}

We have assumed that the central bank distributes all seigniorage revenue lump-sum to the old. ${ }^{20}$ As a result, while the wealth effect of bubble creation expanded investment by redistributing resources to young entrepreneurs, the wealth effect of money creation did not. This was a useful benchmark assumption, which restricted as much as possible the powers of the central bank. We now relax it in two different ways. We first allow the central bank to directly distribute seigniorage revenues to entrepreneurs, thereby directly expanding investment. We then allow the central bank to lend directly to entrepreneurs, which can be interpreted as an "asset purchase scheme" in which seigniorage is used to purchase credit contracts.

20. One interpretation is that the central bank rebates these revenues to the treasury, which then distributes them through tax rebates to the old. 
5.2.1. Transfer of seigniorage to entrepreneurs. Consider the extreme case where the central bank is able to distribute seigniorage directly to young entrepreneurs. Formally, the law of motion of the capital stock in Equation (30) becomes:

$$
k_{t+1}=\frac{1-\frac{m_{t}}{\mu_{t}}-b_{t}+\phi \cdot\left(\varepsilon+n_{t}+\frac{\mu_{t}-1}{\mu_{t}} \cdot m_{t}\right)}{1+\phi} \cdot \frac{1-\alpha}{\gamma} \cdot k_{t}^{\alpha},
$$

where $\frac{\mu_{t}-1}{\mu_{t}} \cdot m_{t}$ is the real value of seignorage and captures the expansionary effect of transferring seigniorage revenues directly to entrepreneurs. The effects of money now mirror those of bubbles: old bubbles $b_{t}$ and old money $\frac{m_{t}}{\mu_{t}}$ have an overhang effect and crowd out investment, whereas new bubbles $n_{t}$ and new money $\frac{\mu_{t}-1}{\mu_{t}} \cdot m_{t}$ have a wealth effect and crowd in investment.

The first observation from Equation (40) is that monetary policy becomes more powerful if the central bank can distribute seigniorage directly to entrepreneurs. Through these transfers, monetary policy can expand the capital stock and mimic the effects of bubble creation. As we argue next, however, this may create equilibrium indeterminacy in the value of money.

To see this, consider the law of motion of real balances in the absence of bubbles (i.e. $b_{t}=n_{t}=0$ for all $t$ and $h^{t}$ ), and for a given constant rate of money growth $\mu$ :

$$
m_{t}=\max \left\{v,\left[1-m_{t}+\phi \cdot \varepsilon+\mathcal{I} \cdot(1+\phi) \cdot \frac{\mu-1}{\mu} \cdot m_{t}\right] \cdot \frac{1-\alpha}{\alpha} \cdot \frac{E_{t} m_{t+1}}{\mu}\right\},
$$

where $v$ is the small demand by money holders and $\mathcal{I}$ is the indicator function that takes value of one if seigniorage is distributed to entrepreneurs and zero otherwise.

When $\mathcal{I}=0$, we are back to our baseline specification, since Equation (40) collapses to Equation (29) as $v$ becomes small. In this case, the second term in the brackets defines $E_{t} m_{t+1}$ as a convex function of $m_{t}$, as illustrated in the left panel of Figure 8 . This in turn is sufficient to ensure that there is a unique value of money balances, denoted by $m^{*}$, which is consistent with competitive equilibrium. If money balances were either above or below $m^{*}$ in any period, then they would eventually either be on an explosive path or decline below $v$ in finite time, both of which are inconsistent with competitive equilibrium.

Things change dramatically, however, when $\mathcal{I}=1$. In this case, the second term in the brackets in Equation (40) may define $E_{t} m_{t+1}$ as a concave function of $m_{t}$, as illustrated in the right panel of Figure $8 .^{21}$ Thus, the equilibrium value of money may then be indeterminate. As the figure shows, there is always a stationary equilibrium in which money is not held as a store of value, i.e., $m_{t}=v$ for all $t$ and $h^{t}$, since then the discounted value of money is less than $v$. But, there also exists a stationary equilibrium in which money is held as a store of value and its value is $m^{*}>v .^{22}$ That is, the monetary policy rule above is no longer decisive.

The intuition for this result is simple. In the first equilibrium, the capital stock is low, and the interest rate is therefore high (relative to the return on money). Thus, agents do not demand real balances as a store of value and seigniorage revenues and thus central bank transfers to entrepreneurs are low, which indeed confirms the low investment and capital stock. In the second equilibrium, instead, the capital stock is high, and the interest rate is therefore low. This boosts the demand for real balances and thus seigniorage revenues, which—given their distribution to entrepreneurs - confirms the high investment and capital stock.

21. The necessary and sufficient condition for this map to be concave and for $m^{*}$ to be greater than $v$ is $\frac{\alpha}{1-\alpha} \cdot \mu-$ $1-\phi \cdot \varepsilon>v \cdot\left(\frac{\phi \cdot(\mu-1)}{\mu}-1\right)$ and $\frac{\phi \cdot(\mu-1)}{\mu}>1$.

22. There is also a continuum of non-stationary equilibria in which $m_{t}$ converges gradually to $m^{*}$ from below. 

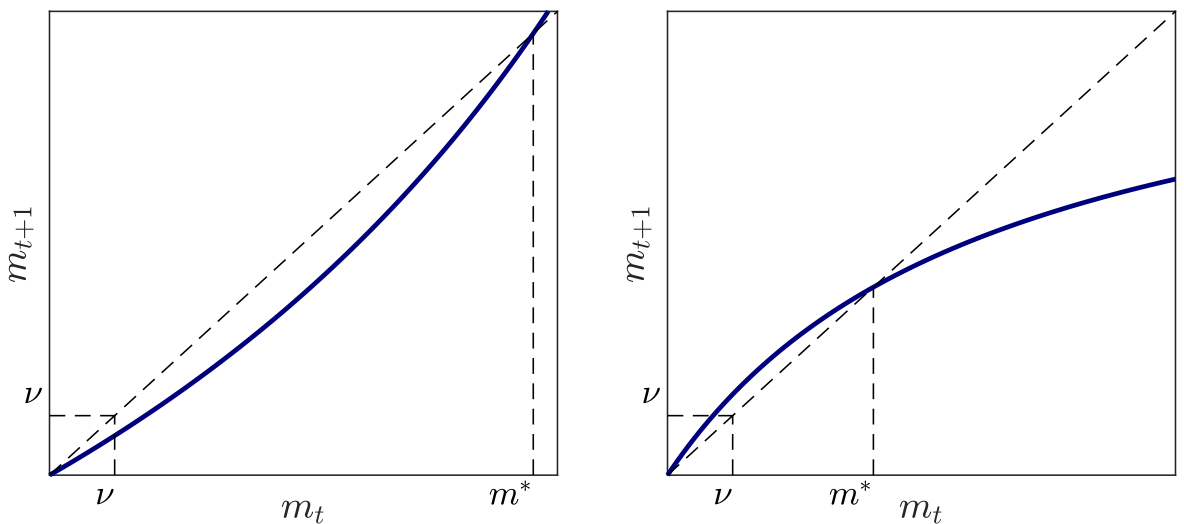

FIGURE 8

This figure illustrates the law of motion for money balances in the absence of bubbles, in two different scenarios. The left panel depicts our benchmark case where the central bank rebates its seignorage revenue to the old, whereas the right panel depicts the case where the central bank rebates the seignorage revenue to the young entrepreneurs.

What is going on? When the central bank distributes seigniorage to entrepreneurs, an expansion in real balances may boost economic activity. But, since higher economic activity also increases the demand for real balances, this may lead to indeterminacy in the value of money. Of course, the central bank can potentially choose a more sophisticated distribution scheme for its seigniorage revenues so as to avoid such problems. The bottom line, however, is that although the ability to transfer seigniorage to entrepreneurs makes monetary policy more powerful, it also introduces the danger of indeterminacy that must be taken into account when thinking about the design of monetary policy.

5.2.2. Asset purchases. We have stressed throughout that monetary policy in our setting is powerful because it can affect the supply of assets available to the private sector. This is different from a standard balance sheet expansion, in which the central bank issues some assets and purchases others, leaving the total supply available to the private sector unchanged. The distinction is key, as it turns out. Although monetary policy interventions that change the supply of stores of value affect capital accumulation, output, and aggregate consumption, policy interventions that merely exchange some stores of value for others do not.

To see this, consider an equilibrium sequence $\left\{b_{t}, n_{t}, m_{t}, \mu_{t}\right\}$-where $\left\{\mu_{t}\right\}$ is the optimal monetary policy of Proposition 4-and suppose that monetary policy is modified through a balance sheet expansion. In particular, the central bank expands the supply of real balances at time $t$ by an amount equal to a share $\omega_{t}$ of wages, and uses all the proceeds to purchase backed debts from entrepreneurs. ${ }^{23}$ At time $t+1$, in turn, the central bank uses the income generated by these debts to purchase back real balances in an amount equal to a share $\omega_{t+1}$ of wages. In this manner, the central bank expands its balance sheet at time $t$ and contracts it at time $t+1$. We want to show that, given the market psychology and the monetary policy rule $\left\{\mu_{t+1}\right\}$, the original equilibrium sequence $\left\{b_{t}, n_{t}, m_{t}, \mu_{t}\right\}$ is still an equilibrium after the intervention.

23. Nothing of substance would change if the central bank would also purchase bubbles. 
Under the proposed intervention, the equilibrium conditions at time $t$ become:

$$
\begin{aligned}
& b_{t}+n_{t}=\left[1-m_{t}-b_{t}+\phi \cdot\left(\varepsilon+n_{t}\right)\right] \cdot \frac{1-\alpha}{\alpha} \cdot E_{t} b_{t+1}, \\
& m_{t}+\omega_{t}=\left[1-m_{t}-b_{t}+\phi \cdot\left(\varepsilon+n_{t}\right)\right] \cdot \frac{1-\alpha}{\alpha} \cdot\left[E_{t}\left\{\frac{m_{t+1}}{\mu_{t+1}}+\widehat{\pi}_{t+1}^{-1} \cdot \omega_{t} \cdot \frac{k_{t}^{\alpha}}{k_{t+1}^{\alpha}}\right\}\right],
\end{aligned}
$$

where $\widehat{\pi}_{t+1}$ indicates the value of inflation after the intervention. ${ }^{24}$ The first observation is that the law of motion of the bubble is unchanged relative to Equation (28). The reason is that, as long as $m_{t}$ and $b_{t}$ do not change, the policy intervention leaves total investment and thus the interest rate unchanged. Hence, the equilibrium growth of the bubble is unaffected. The intervention does not affect investment because, when the central bank purchases credit contracts, savers reduce their lending to entrepreneurs by an equal amount and use these resources instead to hold the real balances injected by the central bank. In a sense, the only thing that changes in period $t$ is that the central bank intermediates between savers and entrepreneurs.

The second observation is that, from Equations (29) and (42), it must hold that:

$$
E_{t}\left\{\widehat{\pi}_{t+1}^{-1}\right\}=E_{t}\left\{\pi_{t+1}^{-1}\right\}
$$

In other words, if the equilibrium interest rate does not change, neither does the expected return on money balances if agents are to continue to hold real balances as a store of value.

To confirm that $\left\{b_{t}, n_{t}, m_{t}, \mu_{t}\right\}$ is indeed an equilibrium of the economy after the intervention, it only remains to show that the path of realized inflation $\widehat{\pi}_{t+1}$ satisfies Equation (43). To see this, note that real balances in period $t+1$ are given by:

$$
m_{t+1}=\frac{\mu_{t+1} \cdot m_{t}+\omega_{t}}{\widehat{\pi}_{t+1}} \cdot \frac{k_{t}^{\alpha}}{k_{t+1}^{\alpha}}-\omega_{t+1}
$$

i.e., real balances at $t+1$ equal the real value of "old money" plus the new money issued by the central bank, where the latter includes the "buybacks" $\omega_{t+1}$ entailed by the intervention. From the budget constraint of the central bank, these "buy backs" are given by:

$$
\omega_{t+1}=\frac{R_{t+1}^{K}}{1+\phi} \cdot \omega_{t} \cdot \frac{k_{t}^{\alpha}}{k_{t+1}^{\alpha}},
$$

i.e., buy backs are equal to the revenues that the central bank earns on the debts that it purchased at $t$. Combining Equations (44) and (45), we have that:

$$
\widehat{\pi}_{t+1}^{-1}=\frac{\pi_{t+1}^{-1} \cdot \mu_{t+1} \cdot m_{t}+E_{t}\left\{\widehat{\pi}_{t+1}^{-1}\right\} \cdot \omega_{t}}{\mu_{t+1} \cdot m_{t}+\omega_{t}} .
$$

Finally, taking expectations and using the fact that $\mu_{t+1}$ is known at time $t$ (see Equation (A.19)), we confirm that Equation (43) is satisfied.

24. To inject $\omega_{t} \cdot(1-\alpha) \cdot k_{t}^{\alpha}$ units of real balances, the central bank sells $p_{t} \cdot \omega_{t} \cdot(1-\alpha) \cdot k_{t}^{\alpha}$ units of nominal money at time $t$, which are worth $\widehat{\pi}_{t+1}^{-1} \cdot \omega_{t} \cdot \frac{k_{t}^{\alpha}}{k_{t+1}^{\alpha}}$ consumption goods as a share of wages at $t+1$. 
This shows that a balance sheet expansion does not affect the evolution of the bubble, real balances, interest rates, or investment. ${ }^{25}$ But it does affect realized inflation in period $t+1$, as Equation (46) shows. The reason is that, even though the central bank's revenues in period $t+1$ suffice in expectation to buy back the real balances that it injected in period $t$, this is not true in all states. In particular, the central bank is unable to buy back $\omega_{t}$ in states in which $\pi_{t+1}^{-1}>E_{t}\left\{\pi_{t+1}^{-1}\right\}$ in the original equilibrium. Ex post, the return to money holdings is so high in these states that the income from the debts held by the central bank is insufficient to buy back the additional money balances that it injected at time $t$. The only way for real balances to remain unchanged relative to the original equilibrium is through higher inflation, i.e., $\widehat{\pi}_{t+1}^{-1}<\pi_{t+1}^{-1}$. The opposite happens in states in which $\pi_{t+1}^{-1}<E_{t}\left\{\pi_{t+1}^{-1}\right\}$, in which case the intervention implies that $\widehat{\pi}_{t+1}^{-1}>\pi_{t+1}^{-1}$.

We have thus shown that that the intervention $\left(\omega_{t}, \omega_{t+1}\right)$ does not affect the equilibrium $\left\{b_{t}, n_{t}, m_{t}, \mu_{t}\right\}$. By affecting realized inflation, however, the intervention does have redistributive effects between old savers and old entrepreneurs. But in our framework this redistribution is irrelevant for the evolution of capital, output, and aggregate consumption.

\subsection{Market psychology}

We have assumed that the central bank cannot affect market psychology. Formally, this implies that the central bank takes the market psychology as given and is constrained to design policies that are consistent with it, and it cannot-for instance-use monetary policy to "prick" bubbles. This assumption has been largely motivated by our general theme of constraining monetary policy as much as possible. But what if we assume instead that the central bank could "shape" the market psychology?

Consider, for instance, that we alter the "timing" of the model so that the central bank sets its policy before market psychology is determined. While in our baseline framework it is market psychology that restricts the set of feasible monetary policies, we can now think of monetary policy as restricting the set of feasible market psychologies. Indeed, through the appropriate design of policy, the central bank can therefore rule out certain bubbles. To see this, suppose for instance that the central bank sets $\mu_{t}=1$ for all $t$ and $h^{t}$, independently of the market psychology. It is then easy to show that this policy rules out all stationary bubbles in equilibrium. The reason is that, under this policy, the return on money is so high that the value of unbacked assets $x_{t}$ would necessarily follow an explosive path should bubbles arise. This policy captures the popular narrative that, by raising interest rates for long enough, the central bank can prick bubbles.

Of course, this raises a number of additional questions. How credible is the central bank's choice of policy? Does it actually need to raise interest rates in equilibrium, or would offequilibrium threats suffice? A thorough treatment of these issues would exceed the scope of this article. But our brief discussion does highlight how, in the bubbly world, the effects of policy crucially depend on whether and how they affect market psychology.

\section{BUBBLES? WHAT BUBBLES?}

To conclude, we provide answers to some frequently asked questions about the scope and relevance of our analysis. We first explain how the theoretical concept of bubbles relates to the sort of assets that are traded every day in financial markets around the world. We then provide some backof-the-envelope calculations intended as a suggestive quantitative exploration of the size of the mechanisms described in this article.

25. Recall that we have assumed that market psychology is chosen first and monetary policy (now also extended to include asset purchases) cannot affect it. 

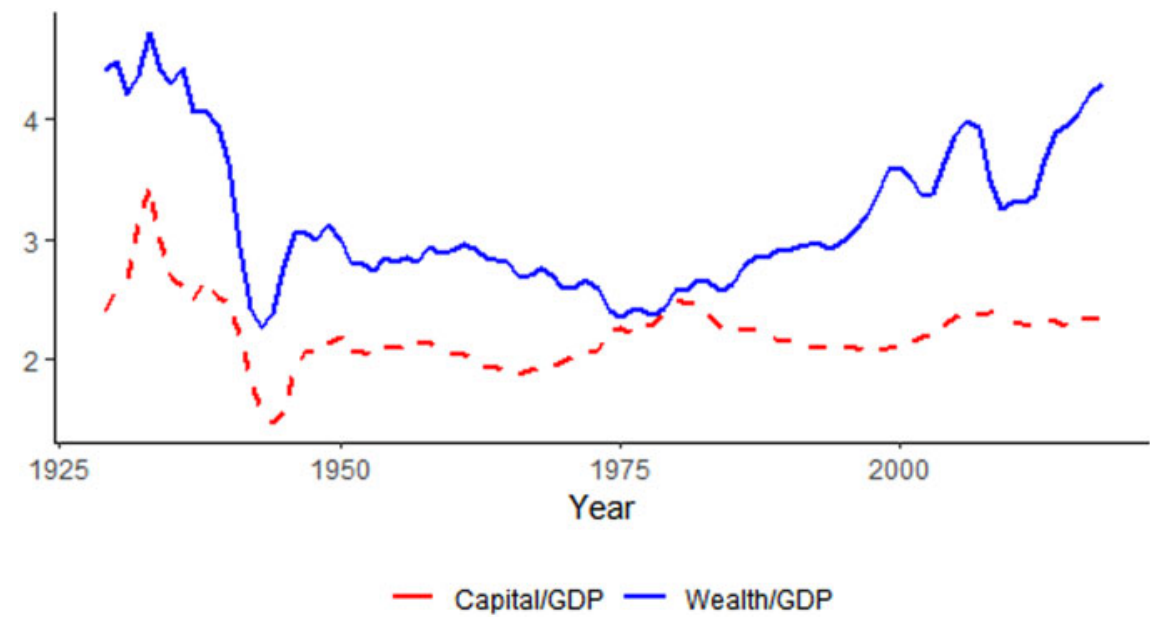

FIGURE 9

This figure illustrates the ratio of Wealth-to-GDP (blue-solid line) and Capital-to-GDP (red-dashed line) in the U.S. for the 1925-2018 period. Data source: Piketty, Saez, and Zucman (2018).

\subsection{Bubbles and national wealth}

Let us now be a bit more explicit about asset structure and how the model fits the data. Figure 9 shows data on the aggregate wealth-income and capital-income ratios for the U.S. for the 19252018 period. These are the variables our theory focuses on. Let $V_{t}$ and $V_{t}^{K}$ denote wealth and the market value of capital, respectively. In our model, these are given by:

$$
\begin{gathered}
V_{t}=V_{t}^{K}+N_{t}+B_{t}+M_{t}, \\
V_{t}^{K}=K_{t+1}^{I}+(1+\phi) K_{t+1}^{E},
\end{gathered}
$$

where $K_{t+1}^{I}$ is the part of the aggregate capital stock that is not monitored (i.e. not useful as collateral), while $K_{t+1}^{E}$ is the part of the aggregate capital stock that is monitored (or useful as collateral). Naturally, we have that the total capital stock is given by $K_{t+1}=K_{t+1}^{I}+K_{t+1}^{E}$. The remaining variables are the aggregate bubble, $N_{t}+B_{t}$, and aggregate money, $M_{t}$.

Figure 9 shows that wealth-income and the capital-income ratios have fluctuated quite a bit over the last century. One can interpret the gap between these ratios as a rough estimate of the value of unbacked assets, i.e., money and bubbles. ${ }^{26}$ Before the great depression of the 1930s, the gap between these ratios was large, consistent with many accounts of this episode as combination of stock market and credit bubbles. The great depression of the 1930s produced a massive drop in both ratios, and also reduced the gap between them. This gap slowly fell until it had basically disappeared in the late 1970s. This is a period in which unbacked assets seem to have played a minor role. Since the 1980s the gap has grown again, especially in the second half of the 1990s and the 2000s. The dotcom bubble of the late 1990s and the stock market and real state bubbles of the mid-2000s further increased the gap, even though the end of each of these episodes ended with a collapse in wealth that temporarily reduced the gap. In the 2010s, the gap has continued to grow and is now larger than ever before.

26. See Carvalho et al. (2012) for an attempt to measure the aggregate bubble in the U.S. for the post-WWII period. Their results are broadly consistent with the gap shown in Figure 9. 
Our theory views these aggregate variables as portfolios of three simple or basic assets: capital, money, and bubbles. Real-world financial structures are more complex, of course. But it is useful to think about them in this way. Perhaps the easiest way to show this is to think of these complex financial structures as "firms" with different dividend and investment policies. We offer next a couple of examples that help clarify the connection between our concept of bubbles and real-world assets. As we go through these examples, one should keep in mind that a bubble is a pyramid scheme in which participants make a voluntary contribution that gives them right to the next voluntary contribution.

The first example is a stock market bubble. We consider a firm, say firm 1, whose stock market value exceeds the cost of replacing the capital it owns. Many would qualify this discrepancy as an overvaluation, even though this stock price is perfectly rational if market participants expect the overvaluation to grow at the required rate of return. Buying today's overvaluation gives stock owners the right to sell tomorrow's overvaluation. Thus, the overvaluation is a bubble. Formally, assume firm 1 is created in period $t=0$ by an entrepreneur who makes an initial investment equal to $I_{1,0}=(1+\phi) \cdot K_{1,1}^{E}$, and sells the entire firm in the stock market. Each period firm 1 distributes dividends $D_{1, t}$ and makes investments $I_{1, t}$. Firm 1 does not borrow from banks and it does not issue additional equity. Thus, it must finance these expenses with profits, that is, sales net of labour costs. The initial stock market value of firm 1 is:

$$
\begin{aligned}
& V_{1,0}=V_{1,0}^{K}+B_{1,0}, \\
& V_{1,0}^{K}=(1+\phi) \cdot K_{1,1}^{E} .
\end{aligned}
$$

The entrepreneur makes a pure profit equal to $B_{1,0}=N_{1}$ when she sells the firm. The replacement value of the initial capital is $V_{1,0}^{K}$, and yet the firm is traded for a value equal to $V_{1,0}>V_{1,0}^{K}$. Since firm 1 uses only external finance, its equity must yield an expected return equal to $R_{t+1}$ :

$$
\begin{aligned}
E_{t}\left\{\frac{V_{1, t+1}+D_{1, t+1}}{V_{1, t}}\right\} & =E_{t}\left\{\frac{(1+\phi) \cdot K_{1, t+2}^{E}+B_{1, t+1}+D_{1, t+1}}{(1+\phi) \cdot K_{1, t+1}^{E}+B_{1, t}}\right\} \\
& =E_{t}\left\{\frac{R_{t+1}^{K} \cdot K_{1, t+1}^{E}+B_{1, t+1}}{(1+\phi) \cdot K_{1, t+1}^{E}+B_{1, t}}\right\} \\
& =\frac{V_{1, t}^{K}}{V_{1, t}^{K}+B_{1, t}} \cdot \frac{R_{t+1}^{K}}{1+\phi}+\frac{B_{1, t}}{V_{1, t}^{K}+B_{1, t}} \cdot \frac{E_{t} B_{1, t+1}}{B_{1, t}} \\
& =R_{t+1} .
\end{aligned}
$$

The first equality simply shows the expected return to equity. The second equality just uses the fact that investment, i.e., $I_{1, t}=(1+\phi) \cdot K_{1 t+2}^{E}$; and dividends, i.e., $D_{1, t+1}$, are financed with profits, i.e., $R_{t+1}^{K} \cdot K_{1, t+1}^{E}$. The third equality just re-arranges the second line in a convenient way to show that the expected return to the equity of firm 1 is a weighted average of the return to its capital and the growth of its overvaluation. Since both of these returns must equal to $R_{t+1}$ in our model economy, the fourth equality follows.

The second example is a credit bubble. We consider now a firm, say firm 2, that borrows in excess of the net present value of its future cash flows. This credit is often described as unsound. But unsound credit is perfectly rational if creditors expect the firm to raise enough unsound credit in the future to repay them. Providing unsound credit today gives creditors the right to receive the unsound credit that others provide tomorrow. Thus, unsound credit is also a bubble. 
Formally, firm 2 is also created in period $t=0$ by an entrepreneur who makes an investment equal to $I_{2,0}=K_{2,1}^{I}$ and borrows from banks $B_{2,0}=N_{2}$. Unlike the entrepreneur that created firm 1 , the entrepreneur that creates firm 2 keeps the firm. Each period, firm 2 pays back its bank loans, distributes dividends $D_{2, t}$ and makes investments $I_{2, t}$. These expenses are financed by profits and additional bank loans. The initial value of firm 2 is given by:

$$
\begin{aligned}
& V_{2,0}=V_{2,0}^{K}+B_{2,0}, \\
& V_{2,0}^{K}=K_{2,0}^{I} .
\end{aligned}
$$

Thus, the entrepreneur makes a pure profit when the firm is created equal to $B_{2,0}=N_{2}$. Future profits are not pledgeable, and yet banks are willing to lend to firm 2 . Since the firm is financed by a combination of internal and external finance, we need to examine the return to each asset separately. Entrepreneurial wealth must deliver a return equal to $R_{t+1}^{K}$, while bank loans must pay an interest rate equal to $R_{t+1}$ :

$$
\begin{aligned}
E_{t}\left\{\frac{V_{2, t+1}+D_{2, t+1}}{V_{2, t}}\right\} & =E_{t}\left\{\frac{K_{2, t+2}^{I}+B_{2, t+1}+D_{2, t+1}}{K_{2, t+1}^{I}+B_{2, t}}\right\} \\
& =E_{t}\left\{\frac{R_{t+1}^{K} \cdot K_{2, t+1}^{I}+B_{2, t+1}}{K_{2, t+1}^{I}+B_{2, t}}\right\} \\
& =\frac{V_{2, t}^{K}}{V_{2, t}^{K}+B_{2, t}} \cdot R_{t+1}^{K}+\frac{B_{2, t}}{V_{2, t}^{K}+B_{2, t}} \cdot \frac{E_{t} B_{2, t+1}}{B_{2, t}} \\
& =\frac{V_{2, t}^{K}}{V_{2, t}^{K}+B_{2, t}} \cdot R_{t+1}^{K}+\frac{B_{2, t}}{V_{2, t}^{K}+B_{2, t}} \cdot R_{t+1} .
\end{aligned}
$$

The first equality simply shows the expected total return to the firm. The second equality just uses the fact that investment, i.e., $I_{2, t}=K_{2, t+2}^{I}$; and dividends, i.e., $D_{2, t+1}$, are financed from profits, i.e., $R_{t+1}^{K} K_{2, t+1}^{I}$. The third equality just re-arranges the second line in a convenient way to show how the total expected return to firm 2 is distributed across assets. Entrepreneurial wealth delivers a return equal to $R_{t+1}^{K}$, while the credit bubble delivers a return equal to its growth rate. The latter must equal to $R_{t+1}$ in our model economy, and this is recognized in the fourth equality.

These examples show that our theory is not only consistent with real-world asset structures, but also that it allows us to interpret them in a novel way. Nothing would change in our model if entrepreneurs created firms of type 1 and 2 (or even more complex financial structures) instead of our simple assets. We adopt the simple asset structure of capital, money, and bubbles because it makes the theory more transparent. We recognize, though, that it will be necessary to map these basic assets to real-world financial assets in specific applications.

\subsection{A back-of-the-envelope calculation}

In this section, we explore further the properties of the model by performing a simple numerical exercise. To be clear, the objective of this exercise is not to provide a careful quantitative evaluation of the framework or to replicate any particular historical event. In fact, both of these tasks would require a much richer model. Rather, our aim is to show that the magnitudes implied by the model are quantitatively relevant and reasonable. 



FIGURE 10

This figure illustrates how the steady-state values of private bubbles, money, and consumption vary with bubble-creation, under optimal monetary policy, in our calibrated economy.

We choose parameter values so that the model, under passive monetary policy, reproduces some salient facts characterizing the U.S. economy in the aftermath of the 2008 financial crisis. Since our model captures medium-run—rather than high-frequency—dynamics, we set the length of a period to 10 years. We set the capital share of output to $\alpha=0.4$ (Karabarbounis and Neiman, 2014). We target a growth rate of output in steady state equal to $3 \%$ per year, consistent with the average growth rate of U.S. real GDP. This implies $\gamma=1.03^{10}$. We set $\phi$ so that the spread between the return to capital and the interest rate is equal to $7 \%$ per year, close to its empirical counterpart, as reported by Farhi and Gourio (2018). Finally, the share of entrepreneurs in the population $(\varepsilon)$ and bubble creation $(\eta)$ are set so that the interest rate is $-1 \%$ per year (Farhi and Gourio, 2018), and the steady state bubble is $100 \%$ of yearly GDP, in line with the difference between wealth and capital observed in the U.S. over the last decade (see Figure 9). This procedure gives $\varepsilon=0.082$ and $\eta=0.081$.

Given this parametrization, we compute the optimal monetary policy in steady state as a function of private bubble creation $(\eta)$. The left panel of Figure 10 shows how the optimal money supply and the private bubble vary as a function of $\eta$. There are two results to notice. First, the size of the monetary interventions under the optimal policy can be substantial. For instance, if the private sector is not producing bubbles at all $(\eta=0)$, the optimal money supply is over $200 \%$ of yearly output. Second, though the optimal money supply falls as private bubble creation increases, monetary interventions remain significant even in the presence of sizable bubbles. As an example, under our baseline calibration, the bubble is equal to $100 \%$ of yearly GDP. Given this value of the bubble, the optimal money supply is around $90 \%$ of yearly output. The overall message is thus that central banks can play an important role in complementing the private supply of assets.

Another interesting question is how the optimal monetary policy affects agents' consumption. The right panel of Figure 10 shows the percent increase in steady state consumption under the optimal policy, compared to its value under the passive monetary policy, again as a function of $\eta$. The key result here is that monetary policy can increase substantially agents' consumption. For instance, under our baseline calibration the optimal monetary policy increases consumption by about $5 \%$. So, optimal monetary policy interventions are not only sizable, but they also lead to significant increases in consumption. 
Of course, given the simplicity of our framework, these results are only illustrative. But they suggest that an interesting area for future research is to explore the quantitative relevance of optimal monetary interventions in a bubbly world, using richer and more realistic models.

More broadly, our analysis identifies a novel role for the central bank as a provider of assets in a bubbly world. Yet, there is much to be done. The policy studied here, for instance, may lead to high inflation volatility. This is not a problem in the model economy considered here because we have abstracted from costs of inflation volatility. To the extent that such costs are important, they may generate a trade-off between the optimal provision of stores of value and the traditional price-stability objective of monetary policy. Also, we have abstracted from the nominal rigidities emphasized in New Keynesian models. To the extent that such rigidities are important, they may introduce a trade-off between the optimal provision of assets and the traditional outputstabilization objective of monetary policy. How should the central bank weight all these objectives when designing its monetary policy? We believe that our framework is a useful starting point for future research aimed at answering this crucial question.

\section{A. APPENDIX}

Proof of Proposition 1 The set $\mathcal{E}$ contains all non-negative sequences $\left\{b_{t}, n_{t}, m_{t}, \mu_{t}\right\}$ that satisfy Equations (16)-(18) and the constraints $\mu_{t} \geq 1$ and $m_{t}+b_{t}<1$ for all $t$ and $h^{t}$. We want to characterize the set $\mathcal{E}$ as a function of the three relevant model parameters: $\alpha, \phi$ and $\varepsilon$. Our strategy is to first characterize a subset $\mathcal{E}_{0} \subseteq \mathcal{E}$ of sequences that satisfy three convenient assumptions. We then show that the results for $\mathcal{E}_{0}$ extend to $\mathcal{E}$.

We make three assumptions that minimize, for each $t$ and $h^{t}$, the largest possible value for $b_{t+1}$ :

1. If there is a history $h^{t+1}$ in which the bubble is smaller than expected, i.e., $b_{t+1}<E_{t} b_{t+1}$; there must be another history $h^{t+1}$ in which it is larger, i.e., $b_{t+1}>E_{t} b_{t+1}$. Thus, we assume that $b_{t+1}=E_{t} b_{t+1}$.

2. New bubbles $n_{t}$ have opposing effects on $b_{t+1}$. Define:

$$
n_{t}(\chi)= \begin{cases}0 & \text { if } b_{t} \leq \frac{1+\phi \cdot \varepsilon-m_{t}}{1+\phi} \\ 1-\varepsilon-m_{t}-b_{t}-\chi & \text { if } \frac{1+\phi \cdot \varepsilon-m_{t}}{1+\phi}<b_{t}<1-\varepsilon-m_{t}, \\ 0 & \text { if } b_{t} \geq 1-\varepsilon-m_{t}\end{cases}
$$

for some small $\chi>0$, which implies some value $b_{t+1}(\chi)$ for the bubble in Equation (16), when bubble creation is equal to $n_{t}(\chi)$. Then, to minimize the bubble, it suffices to take the limiting bubble $b_{t+1} \equiv \lim _{\chi \rightarrow 0} b_{t+1}(\chi)$.

3. Larger values for $m_{t}$ imply larger values for $b_{t+1}$. Thus, we assume that $\left\{\mu_{t}\right\}$ is such that $m_{t}=0$ in each $t$ and $h^{t}$; see Proposition 3 for a proof that such a sequence $\left\{\mu_{t}\right\}$ always exists. Recall that we are looking at equilibria as the share of money holders goes to zero, $v \rightarrow 0$.

Under Assumptions 1-3, we obtain the following law of motion for $b_{t}$ :

$$
b_{t+1}\left\{\begin{array}{ll}
=\frac{\alpha}{1-\alpha} \cdot \frac{b_{t}}{1+\phi \cdot \varepsilon-b_{t}} & \text { if } b_{t} \leq \frac{1+\phi \cdot \varepsilon}{1+\phi} \\
=\frac{\alpha}{1-\alpha} \cdot \frac{1-\varepsilon}{(1+\phi) \cdot\left(1-b_{t}\right)} & \text { if } \frac{1+\phi \cdot \varepsilon}{1+\phi}<b_{t}<1-\varepsilon \\
\in\left[\frac{\alpha}{1-\alpha} \cdot \frac{b_{t}}{(1+\phi) \cdot \varepsilon}, \frac{\alpha}{1-\alpha} \cdot \frac{b_{t}}{\varepsilon}\right] & \text { if } b_{t}=1-\varepsilon \\
=\frac{\alpha}{1-\alpha} \cdot \frac{b_{t}}{1-b_{t}} & \text { if } b_{t}>1-\varepsilon
\end{array} .\right.
$$

Let $\mathcal{E}_{0}=\left\{\left\{b_{t}, n_{t}, m_{t}, \mu_{t}\right\} \in \mathcal{E}: b_{t+1}=E_{t} b_{t+1}, n_{t}=\arg \min E_{t} b_{t+1}\right.$ and $\left.m_{t}=0\right\}$. This set contains all sequences that satisfy the law of motion in Equation (A.2) and the constraint $b_{t}<1$ for all $t$ and $h^{t}$. Figure A1 depicts the map $b_{t} \mapsto b_{t+1}$ implied by the law of motion in Equation (A.2), under the three different parameter conditions stated in Proposition 1.

- The left panel illustrates a case in which:

$$
\frac{\alpha}{1-\alpha}>\max \left\{1+\phi \cdot \varepsilon, \frac{1}{4} \cdot \frac{1+\phi}{1-\varepsilon}\right\} .
$$

This parametric condition ensures that the map $b_{t} \mapsto b_{t+1}$ lies entirely above the $45^{\circ}$ line. Thus, any initial value $b_{0}>0$ would generate an explosive path for the bubble. Hence, all sequences in $\mathcal{E}_{0}$ are such that $b_{t}=0$ for all $t$ and $h^{t}$. 
ASRIYAN ET AL.



MONETARY POLICY FOR A BUBBLY WORLD
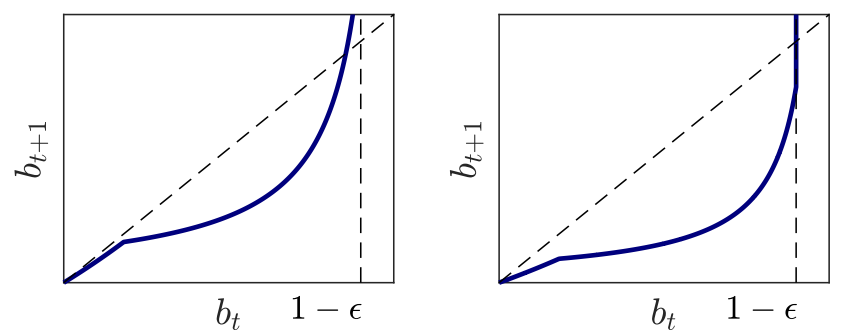

FIGURE A1

This figure illustrates the law of motion of the bubble given in Equation (A.2) under the three cases considered in the proof of Proposition 3.

- The middle panel illustrates a case in which:

$$
(1+\phi) \cdot \varepsilon<\frac{\alpha}{1-\alpha}<\max \left\{1+\phi \cdot \varepsilon, \frac{1}{4} \cdot \frac{1+\phi}{1-\varepsilon}\right\}
$$

This parametric condition ensures that the map $b_{t} \mapsto b_{t+1}$ lies above the $45^{\circ}$ whenever $b_{t} \geq 1-\varepsilon$. Thus, any initial value $b_{0} \in\left[0, b^{\max }\right]$, where $b^{\max }$ is the largest fixed point of the map, generates a non-explosive path for the bubble. As a result, sequences such that $b_{t}>0$ for some $t$ and $h^{t}$ are also in $\mathcal{E}_{0}$. Since $b^{\max }<1-\varepsilon$, it must be the case that $b_{t}+n_{t} \leq 1-\varepsilon$ for all $t$ and $h^{t}$. Hence, the economy must always remain in the first regime described in Section 2.2 , where $R_{t+1}=\frac{R_{t+1}^{K}}{1+\phi}$.

- The right panel illustrates a case in which:

$$
\frac{\alpha}{1-\alpha}<(1+\phi) \cdot \varepsilon
$$

This parametric condition ensures that the map $b_{t} \mapsto b_{t+1}$ lies entirely below the $45^{\circ}$ line whenever $b_{t}<1-\varepsilon$ Thus, any initial value $b_{0} \in[0,1-\varepsilon]$ generates a non-explosive path for the bubble. As a result, sequences such that $b_{t} \geq 1-\varepsilon$ for some $t$ and $h^{t}$ are also in $\mathcal{E}_{0}$. Hence, the economy can be outside of the first regime described in Section 2.2, where $R_{t+1}>\frac{R_{t+1}^{K}}{1+\phi}$.

The next observation is that violations of Assumptions 1-3 shift the map $b_{t} \mapsto b_{t+1}$ upwards. Thus, if a bubbly equilibrium does not exist when Assumptions 1-3 hold, it cannot exist when these assumptions are violated. Similarly, if a bubbly equilibrium does not exist outside of the first regime described in Section 2.2 when Assumptions 1-3 hold, it cannot exist outside of the first regime when these assumptions are violated. Thus, we can extend our results from the set $\mathcal{E}_{0}$ to the set $\mathcal{E}$.

Finally, when a bubbly equilibrium does not exist, it must also be that $m_{t}=0$ for all $t$ and $h^{t}$. By arguments similar to above, the most favourable conditions for an equilibrium with $m_{t}>0$ for some $t$ and $h^{t}$ to exist is that $\mu_{t+1}=1$ and $m_{t+1}=E_{t} m_{t+1}$ for all $t$ and $h^{t}$. If $\frac{\alpha}{1-\alpha}>\max \left\{1+\phi \cdot \varepsilon, \frac{1}{4} \cdot \frac{1+\phi}{1-\varepsilon}\right\}$, then $b_{t}=n_{t}=0$ as we have shown above. But then, by inspection of Equations (17)-(18), the law of motion $m_{t} \mapsto m_{t+1}$ implies an explosive path for $m_{t}$, starting from any $m_{0}>0$, as it is the same law of motion as for $b_{t}$ but with $n_{t}$ set to zero. If $\frac{\alpha}{1-\alpha}>(1+\phi) \cdot \varepsilon$ and the economy is outside of the first regime described in Section 2.2, then $b_{t}=n_{t}=0$ as we have shown above. But then, by inspection of Equations (17)-(18), the law of motion $m_{t} \mapsto m_{t+1}$ is explosive starting from any $m_{0} \geq 1-\varepsilon$, a contradiction.

Proof of Proposition 2 Using the arguments in the proof of Proposition 1, it is clear that the market psychology $\mathcal{P}$ is feasible whenever $\mathcal{E}^{\mathcal{M}, \mathcal{P}} \subset \mathcal{E}^{\mathcal{P}}$ contains sequences $\left\{b_{t}, n_{t}, m_{t}, \mu_{t}\right\}$ with $m_{t}=0$ for all $t$ and $h^{t}$. In what follows, therefore, without loss of generality we set $m_{t}=0$ for all $t$ and $h^{t}$.

Suppose that $\mathcal{P}$ is feasible but that $\Gamma_{s}<0$ for some $s$. The law of motion for the bubble, given in Equation (16), along the sample path in which $u_{t}=u_{s}$ and $n_{t}=n_{s}$ for all $t$ is:

$$
b_{t+1}=u_{s} \cdot \frac{\alpha}{1-\alpha} \cdot \frac{b_{t}+n_{s}}{1+\phi \cdot\left(\varepsilon+n_{s}\right)-b_{t}},
$$

where we have used the fact that the economy is always in the first regime described in Section 2.2 . Since $\Gamma_{s}<0$, it is easy to check that the map $b_{t} \mapsto b_{t+1}$ induced by Equation (A.6) lies everywhere above the $45^{\circ}$ line. Hence, along this sample path the bubble is explosive, a contradiction.

Suppose that $\mathcal{P}$ is feasible but that $b_{L}>b_{H}$. Consider the following sample path for the bubble. For $t \in\{0, \ldots, T\}$, set $u_{t}=u_{s}$ and $n_{t}=n_{s}$ corresponding to state $s$ such that $b_{L, s}=b_{L}$. For $t>T$, set $u_{t}=u_{s^{\prime}}$ and $n_{t}=n_{s^{\prime}}$ corresponding to state 
$s^{\prime}$ such that $b_{H, s^{\prime}}=b_{H}$. Observe that, for $T$ large enough, it must be that $b_{T} \approx b_{L}>b_{H}$. But then, the map $b_{t} \mapsto b_{t+1}$ for law of motion of the bubble must lie above the $45^{\circ}$ line for $b_{t}>b_{H}$ and $t>T$. Hence, along this sample path the bubble is explosive, a contradiction.

Suppose that $\mathcal{P}$ is feasible but that $\beta>b_{H}$. But then the map $b_{t} \mapsto b_{t+1}$ for the law of motion of the bubble along the sample path in which $u_{t}=u_{s}$ and $n_{t}=n_{s}$ for all $t>0$ and corresponding to state $s$ such that $b_{H, s}=b_{H}$ lies above the $45^{\circ}$ line for $b_{t}>b_{H}$. Hence, along this sample path the bubble is explosive, a contradiction.

Finally, suppose that $\Gamma_{s} \geq 0$ for all $s, b_{0} \leq b_{H}$ and $b_{H} \geq b_{L}$. But then, it is straighforward to show that Equation (A.6) implies $b_{t}<1$ for all $t$ and $h^{t}$, i.e., $\mathcal{P}$ is feasible.

Proof of Proposition 3 Fix a feasible market psychology $\mathcal{P}(\beta, \mathcal{S}, \mathcal{T})$, and let $b_{0}^{*}=\beta$ and $\left\{u_{s}, n_{s}\right\}$ denote the initial condition for the bubble and the bubble return- and creation-shocks associated with this market psychology, respectively. Consider now a candidate competitive equilibrium in which $m_{t}=0$ for all $t$ and $h^{t}$, and let $\left\{b_{t}^{*}, n_{t}\right\}$ denote the associated equilibrium sequence for the bubble, computed using Equation (16), for a given history of bubble shocks. Consider a sequence $\left\{\mu_{t}^{*}\right\}$ that satisfies $\mu_{t}^{*} \geq 1$ and:

$$
\mu_{t+1}^{*}>\frac{1-\alpha}{\alpha} \cdot\left(1+\phi \cdot\left(\varepsilon+n_{t}\right)-b_{t}^{*}\right)
$$

for all $t$ and $h^{t}$. Thus, $\left\{\mu_{t}^{*}\right\}$ is a stochastic sequence whose sample path depends solely on $b_{0}^{*}=\beta$ and the realized history of the bubble shocks, $\left\{u_{t}, n_{t}\right\}$. By inspection of Equations (16)-(18), together with the parametric assumption in part (2.i) of Proposition 1, we see that the candidate values for the bubble and money balances are indeed part of a competitive equilibrium. We next show that this equilibrium is unique, and we proceed to do so by contradiction.

Suppose to the contrary that, given the sequence $\left\{\mu_{t}^{*}\right\}$ satisfying condition (A.7), there exists another competitive equilibrium in which, in some period $t_{0}$, we have $m_{t_{0}}>0$ for the first time. Let $\left\{b_{t}, n_{t}\right\}$ denote the associated equilibrium sequence for the bubble, again computed using Equation (28). Notice that by assumption we have that $m_{t}=0$ and $b_{t}=b_{t}^{*}$ for all $t \leq t_{0}$. From Equations (28)-(29), it must be that:

$$
\begin{aligned}
E_{t_{0}} m_{t_{0}+1} & =\frac{\alpha}{1-\alpha} \cdot \frac{\mu_{t_{0}+1}^{*} \cdot m_{t_{0}}}{1+\phi \cdot\left(\varepsilon+n_{t_{0}}\right)-\left(b_{t_{0}}+m_{t_{0}}\right)} \\
& >\frac{1+\phi \cdot\left(\varepsilon+n_{t_{0}}\right)-b_{t_{0}}^{*}}{1+\phi \cdot\left(\varepsilon+n_{t_{0}}\right)-\left(b_{t_{0}}+m_{t_{0}}\right)} \cdot m_{t_{0}} \\
& \equiv\left(1+\gamma_{t_{0}+1}\right) \cdot m_{t_{0}},
\end{aligned}
$$

where, because $b_{t_{0}} \geq b_{t_{0}}^{*}$ and $m_{t_{0}}>0$, we have that:

$$
\gamma_{t_{0}+1}=\frac{\left(b_{t_{0}}+m_{t_{0}}\right)-b_{t_{0}}^{*}}{1+\phi \cdot\left(\varepsilon+n_{t_{0}}\right)-\left(b_{t_{0}}+m_{t_{0}}\right)}>0 .
$$

Thus, there exists a (continuation) state at $t_{0}+1$ that must occur with positive probability such that $b_{t_{0}+1} \geq b_{t_{0}+1}^{*}($ see Equation (28)) and such that:

$$
m_{t_{0}+1}>\left(1+\gamma_{t_{0}+1}\right) \cdot m_{t_{0}} .
$$

Proceeding inductively, we can construct a sample path in which, for $t>t_{0}$, we have $b_{t} \geq b_{t}^{*}$ and:

$$
m_{t+1} \geq\left(1+\gamma_{t+1}\right) \cdot m_{t},
$$

and where:

$$
\gamma_{t+1}=\frac{\left(b_{t}+m_{t}\right)-b_{t}^{*}}{1+\phi \cdot\left(\varepsilon+n_{t}\right)-\left(b_{t}+m_{t}\right)}>0 .
$$

Since along this path $m_{t}>m_{t_{0}}$ and $b_{t} \geq b_{t}^{*}$, it follows that:

$$
\inf _{t \geq t_{0}} \gamma_{t+1} \geq \frac{m_{t_{0}}}{1+\phi \cdot\left(\varepsilon+\max _{s \in \mathcal{S}} n_{s}\right)}>0
$$

Thus, it must be that $\lim _{t \rightarrow \infty} m_{t}=\infty$, a contradiction.

Proof of Proposition 4 Fix a market psychology $\mathcal{P}$ and consider the candidate asset supply $x_{\mathcal{P}}^{*}$, given by Proposition 4. We first show that there does not exist another feasible sequence $\left\{x_{t}\right\}$ for the total supply of unbacked assets that Pareto-improves on $x_{\mathcal{P}}^{*}$, i.e., such that it strictly increases the consumption of some generation without reducing it for another. 
Case 1. Suppose that $\max _{s \in S} \Omega\left(n_{s}\right)<b_{H}$, so that $x_{\mathcal{P}}^{*}=\max \left\{b_{L}, \max _{s \in S} \Omega\left(n_{s}\right)\right\}$. Consider a sequence of policy changes $\left\{\delta_{t}\right\}$ to the asset supply such that $\delta_{0}>0 .{ }^{27}$ To ensure that these policy changes produce a Pareto-improvement, the consumption of all subsequent generations cannot be smaller after the policy changes:

$$
\begin{aligned}
{\left[\alpha+\left(x_{\mathcal{P}}^{*}+\delta_{t}\right) \cdot(1-\alpha)\right] \cdot \prod_{\tau=0}^{t-1}\left[1+\phi \cdot\left(\varepsilon+n_{\tau}\right)-\left(x_{\mathcal{P}}^{*}+\delta_{\tau}\right)\right]^{\alpha^{(t-\tau)}} } & \\
& \geq\left[\alpha+x_{\mathcal{P}}^{*} \cdot(1-\alpha)\right] \cdot \prod_{\tau=0}^{t-1}\left[1+\phi \cdot\left(\varepsilon+n_{\tau}\right)-x_{\mathcal{P}}^{*}\right]^{\alpha^{(t-\tau)}}
\end{aligned}
$$

for all $t$ and $h^{t}$ (see Equations (30)-(31)). Since, it is without loss of generality to consider sequences $\left\{\delta_{t}\right\}$ such that the above inequality holds with strict equality, a sequence of policy changes $\left\{\delta_{t}\right\}$ produces a Pareto-improvement if and only if: 28

for all $t$ and $h^{t}$.

$$
\delta_{t+1}=\left[\left(\frac{1+\phi \cdot\left(\varepsilon+n_{t}\right)-x_{\mathcal{P}}^{*}}{1+\phi \cdot\left(\varepsilon+n_{t}\right)-\left(x_{\mathcal{P}}^{*}+\delta_{t}\right)} \cdot \frac{\alpha+\left(x_{\mathcal{P}}^{*}+\delta_{t}\right) \cdot(1-\alpha)}{\alpha+x_{\mathcal{P}}^{*} \cdot(1-\alpha)}\right)^{\alpha}-1\right] \cdot\left(\frac{\alpha}{1-\alpha}+x_{\mathcal{P}}^{*}\right)
$$

We now ask whether such a perturbation is feasible, i.e., whether it does not imply an explosive path for the new sequence $\left\{x_{\mathcal{P}}^{*}+\delta_{t}\right\}$. Define the following function:

$$
\Delta\left(\delta_{t} ; x_{\mathcal{P}}^{*}, n_{t}\right)=\left[\left(\frac{1+\phi \cdot\left(\varepsilon+n_{t}\right)-x_{\mathcal{P}}^{*}}{1+\phi \cdot\left(\varepsilon+n_{t}\right)-\left(x_{\mathcal{P}}^{*}+\delta_{t}\right)} \cdot \frac{\alpha+\left(x_{\mathcal{P}}^{*}+\delta_{t}\right) \cdot(1-\alpha)}{\alpha+x_{\mathcal{P}}^{*} \cdot(1-\alpha)}\right)^{\alpha}-1\right] \cdot\left(\frac{\alpha}{1-\alpha}+x_{\mathcal{P}}^{*}\right)
$$

which is the RHS of Condition (A.15) and note that $\Delta\left(\cdot ; x_{\mathcal{P}}^{*}, n_{t}\right)$ is increasing and convex for $\delta_{t}<1+\phi \cdot\left(\varepsilon+n_{t}\right)-x_{\mathcal{P}}^{*}$ (all feasible $\delta_{t}$ satisfy this condition). Therefore, if $\lim _{t \rightarrow \infty} \delta_{t+1}$ is infinite for all $\delta_{0}>0$, then there does not exist a feasible sequence $\left\{\delta_{t}\right\}$ that satisfies Condition (A.15). If $x_{\mathcal{P}}^{*}$ is such that for $t$ sufficiently large $\left.\frac{\partial \Delta}{\partial \delta_{t}}\right|_{\delta_{t}=0} \geq 1$ for all $h^{t}$, then $\lim _{t \rightarrow \infty} \delta_{t+1}$ is infinite for any $\delta_{0}>0$; hence, this implies that $x_{\mathcal{P}}^{*}$ is Pareto efficient. But, since $\left.\frac{\partial \Delta}{\partial \delta_{t}}\right|_{\delta_{t}=0}=\frac{\alpha}{1-\alpha} \cdot \frac{1+\phi \cdot\left(\varepsilon+n_{t}\right) \cdot(1-\alpha)}{1+\phi \cdot\left(\varepsilon+n_{t}\right)-x_{\mathcal{P}}^{*}}$, this is equivalent to saying that for $t$ sufficiently large $x_{\mathcal{P}}^{*} \geq \Omega\left(n_{t}\right)$ for all $h^{t}$, which holds by assumption.

Case 2. Suppose that $\max _{s \in \mathcal{S}} \Omega\left(n_{s}\right)>b_{H}$, so that $x_{\mathcal{P}}^{*}=b_{H}$. Consider an alternative sequence $\left\{\widehat{x}_{t}\right\}$ for the total supply of unbacked assets and let $t_{0}$ be the first period in which $\widehat{x}_{t_{0}}>b_{H}$ along some history $h^{t_{0}} .^{29}$ Suppose that there were a continuation sample path along which $\widehat{x}_{t}>b_{H}$ for $t \geq t_{0}$. Then the law of motion of the bubble along this sample path would be:

$$
\begin{aligned}
b_{t+1} & =u_{t+1} \cdot \frac{\alpha}{1-\alpha} \cdot \frac{b_{t}+n_{t}}{1+\phi \cdot\left(\varepsilon+n_{t}\right)-\widehat{x}_{t}} \\
& >u_{t+1} \cdot \frac{\alpha}{1-\alpha} \cdot \frac{b_{t}+n_{t}}{1+\phi \cdot\left(\varepsilon+n_{t}\right)-b_{H}},
\end{aligned}
$$

which must be explosive (see Proposition 2), a contradiction. Thus, the asset supply cannot exceed $b_{H}$ indefinitely.

Suppose instead that there were continuation sample paths such that $\widehat{x}_{t_{0}+q}>b_{H}$ for all $0 \leq q<\tau$ but that $\widehat{x}_{t_{0}+\tau} \leq b_{H}$, for some $\tau>0$. Take the sample path with largest such $\tau$, which must be finite by our previous argument. Consider the expected consumption of the generation born at time $\tau-1$ along this sample path. These agents expect the asset supply to be less than $b_{H}$ with probability one in period $\tau$. Moreover, since along this sample path the asset supply has been greater than $b_{H}$ until period $\tau$, it must be that the capital stock and thus wages have been lower as well than with asset supply $b_{H}$ (see Equation (30)). From Equation (31), it follows that the expected consumption of these agents must be strictly lower than with asset supply $b_{H}$. Therefore, $\left\{\widehat{x}_{t}\right\}$ does not generate a Pareto-improvement over $b_{H}$.

Next, we construct a monetary policy rule that is decisive in implementing the desired supply for unbacked assets. Fix the market psychology $\mathcal{P}$ and consider the candidate equilibrium in which the value of unbacked assets is $x_{\mathcal{P}}^{*}$ for all $t$

27. A non-trivial sequence of policy changes must have a non-zero term at some point. What is required is that the first non-zero term of the sequence be strictly positive. Otherwise, the policy changes cannot a produce a Pareto improvement since the first generation affected is worse off. If the first non-zero term happens in period $t \neq 0$, all the arguments that follow go through after a simple re-labelling of the time index.

28. To do this, for each history $h^{t}$, divide the condition for period $t+1$ by its counterpart for period $t$ raised to the exponent $\alpha$. Then re-arrange to solve for $\delta_{t+1}$.

29. Pareto-improvement over the asset supply $x_{\mathcal{P}}^{*}$ requires that $\widehat{x}_{t_{0}}>x_{\mathcal{P}}^{*}$ (with positive probability); otherwise, the old agents in the period where the change in the asset supply occurs would be worse off. 
and $h^{t}$. Let $b_{t}^{*}$ and $m_{t}^{*}$ denote the associated candidate equilibrium values of the bubble and money balances, respectively, so that $b_{t}^{*}+m_{t}^{*}=x_{\mathcal{P}}^{*}$. Define a sequence $\left\{\mu_{t}^{*}\right\}$ as follows:

$$
\mu_{t+1}^{*}=\frac{1-\alpha}{\alpha} \cdot\left(1+\phi \cdot\left(\varepsilon+n_{t}\right)-x_{\mathcal{P}}^{*}\right) \cdot \frac{E_{t}\left\{x_{\mathcal{P}}^{*}-b_{t+1}^{*}\right\}}{x_{\mathcal{P}}^{*}-b_{t}^{*}}
$$

for all $t$ and $h^{t}$. Note that, given the market psychology, $\left\{\mu_{t}^{*}\right\}$ is a sequence of numbers that depends only on the history of the shocks $\left\{u_{t}, n_{t}\right\}$. From Equations (28)-(29), given the sequence $\left\{\mu_{t}^{*}\right\}$, we see that the candidate values for the bubble and money balances are indeed part of competitive equilibrium. We next show that the competitive equilibrium is unique, which boils down to showing that, given the market psychology $\mathcal{P}$ and the sequence $\left\{\mu_{t}^{*}\right\}$, the equilibrium value of money balances is pinned down uniquely. We proceed by contradiction.

Suppose to the contrary that, given the market psychology and the monetary policy rule, there is another competitive equilibrium in which in some period $t_{0}$ we have that $m_{t_{0}}>m_{t_{0}}^{*}$ for the first time. Note that $m_{t}=m_{t}^{*}$ and $b_{t}=b_{t}^{*}$ for $t \leq t_{0}$. From Equation (29), it must be that:

$$
\begin{aligned}
E_{t_{0}} m_{t_{0}+1} & =\frac{\alpha}{1-\alpha} \cdot \frac{\mu_{t_{0}+1}^{*} \cdot m_{t_{0}}}{1+\phi \cdot\left(\varepsilon+n_{t_{0}}\right)-\left(b_{t_{0}}+m_{t_{0}}\right)} \\
& \geq \frac{1+\phi \cdot\left(\varepsilon+n_{t_{0}}\right)-\left(b_{t_{0}}^{*}+m_{t_{0}}^{*}\right)}{1+\phi \cdot\left(\varepsilon+n_{t_{0}}\right)-\left(b_{t_{0}}+m_{t_{0}}\right)} \cdot m_{t_{0}} \cdot \frac{E_{t_{0}} m_{t_{0}+1}^{*}}{m_{t_{0}}^{*}} \\
& =\left(1+\gamma_{t_{0}+1}^{+}\right) \cdot m_{t_{0}} \cdot \frac{E_{t_{0}} m_{t_{0}+1}^{*}}{m_{t_{0}}^{*}}
\end{aligned}
$$

where, because $b_{t_{0}} \geq b_{t_{0}}^{*}$ and $m_{t_{0}}>m_{t_{0}}^{*}$, we have that:

$$
\gamma_{t_{0}+1}^{+}=\frac{\left(b_{t_{0}}+m_{t_{0}}\right)-\left(b_{t_{0}}^{*}+m_{t_{0}}^{*}\right)}{1+\phi \cdot\left(\varepsilon+n_{t_{0}}\right)-\left(b_{t_{0}}+m_{t_{0}}\right)}>0 .
$$

Thus, there exists a (continuation) state at $t_{0}+1$ that occurs with positive probability such that $b_{t_{0}+1} \geq b_{t_{0}+1}^{*}$ (see Equation (28)) and such that:

$$
\frac{m_{t_{0}+1}}{m_{t_{0}+1}^{*}} \geq\left(1+\gamma_{t_{0}+1}^{+}\right) \cdot \frac{m_{t_{0}}}{m_{t_{0}}^{*}},
$$

which also implies that $m_{t_{0}+1}>m_{t_{0}+1}^{*}$. Proceeding inductively, we can construct a sample path in which, for $t>t_{0}$, we have that $b_{t} \geq b_{t}^{*}$ :

which implies $m_{t+1}>m_{t+1}^{*}$ and where:

$$
\frac{m_{t+1}}{m_{t+1}^{*}} \geq\left(1+\gamma_{t+1}^{+}\right) \cdot \frac{m_{t}}{m_{t}^{*}}
$$

$$
\gamma_{t+1}^{+}=\frac{\left(b_{t}+m_{t}\right)-\left(b_{t}^{*}+m_{t}^{*}\right)}{1+\phi \cdot\left(\varepsilon+n_{t}\right)-\left(b_{t}+m_{t}\right)}>0 .
$$

Since along this path $m_{t}=\frac{m_{t}}{m_{t}^{*}} \cdot m_{t}^{*} \geq\left(\Pi_{j=1}^{t-t_{0}}\left(1+\gamma_{t_{0}+j}^{+}\right) \cdot \frac{m_{t_{0}}}{m_{t_{0}}^{*}}\right) \cdot m_{t}^{*}>\left(1+\gamma_{t_{0}+1}^{+}\right) \cdot \frac{m_{t_{0}}}{m_{t_{0}}^{*}} \cdot m_{t}^{*}$, it follows that:

$$
\inf _{t \geq t_{0}} \gamma_{t+1}^{+} \geq \frac{\left(1+\gamma_{t_{0}+1}^{+}\right) \cdot \frac{m_{t_{0}}}{m_{t_{0}}^{*}}-1}{1+\phi \cdot\left(\varepsilon+\max _{s \in \mathcal{S}} n_{s}\right)} \cdot v>0 .
$$

Thus, $\lim _{t \rightarrow \infty} \Pi_{j=0}^{t-t_{0}-1}\left(1+\gamma_{t_{0}+j}^{+}\right)=\infty$ and therefore $\lim _{t \rightarrow \infty} \frac{m_{t}}{m_{t}^{*}}=\infty$, which implies that $\lim _{t \rightarrow \infty} m_{t}=\infty$. Thus, this sample path for money balances is explosive, a contradiction.

Second, suppose to the contrary that, given the market psychology and the monetary rule, there is another competitive equilibrium, in which in some period $t_{0}$ we have that $m_{t_{0}}<m_{t_{0}}^{*}$ for the first time. Note that $m_{t}=m_{t}^{*}$ and $b_{t}=b_{t}^{*}$ for $t<t_{0}$. Hence, it must be the case that:

$$
\begin{aligned}
E_{t_{0}} m_{t_{0}+1} & \leq \frac{\alpha}{1-\alpha} \cdot \frac{\mu_{t_{0}+1}^{*} \cdot m_{t_{0}}}{1+\phi \cdot\left(\varepsilon+n_{t_{0}}\right)-\left(b_{t_{0}}+m_{t_{0}}\right)} \\
& \leq \frac{1+\phi \cdot\left(\varepsilon+n_{t_{0}}\right)-\left(b_{t_{0}}^{*}+m_{t_{0}}^{*}\right)}{1+\phi \cdot\left(\varepsilon+n_{t_{0}}\right)-\left(b_{t_{0}}+m_{t_{0}}\right)} \cdot m_{t_{0}} \cdot \frac{E_{t_{0}} m_{t_{0}+1}^{*}}{m_{t_{0}}^{*}} \\
& =\left(1-\gamma_{t_{0}+1}^{-}\right) \cdot m_{t_{0}} \cdot \frac{E_{t_{0}} m_{t_{0}+1}^{*}}{m_{t_{0}}^{*}}
\end{aligned}
$$


where the first inequality is an equality if $m_{t_{0}}>v \approx 0$, and where, because $b_{t_{0}} \leq b_{t_{0}}^{*}$ and $m_{t_{0}}<m_{t_{0}}^{*}$, we have that:

$$
\gamma_{t_{0}+1}^{-}=\frac{\left(b_{t_{0}}^{*}+m_{t_{0}}^{*}\right)-\left(b_{t_{0}}+m_{t_{0}}\right)}{1+\phi \cdot\left(\varepsilon+n_{t_{0}}\right)-\left(b_{t_{0}}+m_{t_{0}}\right)}>0 .
$$

Thus, there must exist a (continuation) state at $t_{0}+1$ that occurs with positive probability such that $b_{t_{0}+1} \leq b_{t_{0}+1}^{*}$ (again, see Equation (28)) and such that:

$$
\frac{m_{t_{0}+1}}{m_{t_{0}+1}^{*}} \leq\left(1-\gamma_{t_{0}+1}^{-}\right) \cdot \frac{m_{t_{0}}}{m_{t_{0}}^{*}}
$$

which also implies that $m_{t_{0}+1}<m_{t_{0}+1}^{*}$. Proceeding inductively, we can construct a sample path in which, for $t>t_{0}$, we have that $b_{t} \leq b_{t}^{*}$ :

$$
\frac{m_{t+1}}{m_{t+1}^{*}} \leq\left(1-\gamma_{t+1}^{-}\right) \cdot \frac{m_{t}}{m_{t}^{*}}
$$

which implies $m_{t+1}<m_{t+1}^{*}$ and where:

$$
\gamma_{t+1}^{-}=\frac{\left(b_{t}^{*}+m_{t}^{*}\right)-\left(b_{t}+m_{t}\right)}{1+\phi \cdot\left(\varepsilon+n_{t}\right)-\left(b_{t}+m_{t}\right)}>0 .
$$

Since along this path $m_{t}=\frac{m_{t}}{m_{t}^{*}} \cdot m_{t}^{*} \leq\left(\Pi_{j=1}^{t-t_{0}}\left(1-\gamma_{t_{0}+j}^{-}\right) \cdot \frac{m_{t_{0}}}{m_{t_{0}}^{*}}\right) \cdot m_{t}^{*}<\left(1-\gamma_{t_{0}+1}^{-}\right) \cdot \frac{m_{t_{0}}}{m_{t_{0}}^{*}} \cdot m_{t}^{*}$, it follows that:

$$
\inf _{t \geq t_{0}} \gamma_{t+1}^{-} \geq \frac{1-\left(1-\gamma_{t_{0}+1}^{-}\right) \cdot \frac{m_{t_{0}}}{m_{t_{0}}^{*}}}{1+\phi \cdot\left(\varepsilon+\max _{s \in \mathcal{S}} n_{s}\right)} \cdot v>0 .
$$

Thus, $\lim _{t \rightarrow \infty} \Pi_{j=0}^{t-t_{0}-1}\left(1-\gamma_{t_{0}+j}^{-}\right)=0$ and therefore $\lim _{t \rightarrow \infty} \frac{m_{t}}{m_{t}^{*}}=0$, which implies that $\lim _{t \rightarrow \infty} m_{t}=0<v$. Thus, money balances are eventually below the money holders' demand, a contradiction.

Finally, we are left to verify that the sequence $\left\{\mu_{t}^{*}\right\}$ is such that seignorage is non-negative at all times, i.e., $\mu_{t}^{*} \geq 1$ for all $t$ and $h^{t}$. Using the law of motion for the bubble in Equation (28) and combining it with the monetary policy rule in Equation (A.19), we have that:

$$
\mu_{t+1}^{*}=\frac{x_{\mathcal{P}}^{*} \cdot\left[1+\phi \cdot\left(\varepsilon+n_{t}\right)-x_{\mathcal{P}}^{*}\right] \cdot \frac{1-\alpha}{\alpha}-\left(b_{t}^{*}+n_{t}\right)}{x_{\mathcal{P}}^{*}-b_{t}^{*}},
$$

where

$$
b_{t+1}^{*}=u_{t+1} \cdot \frac{\alpha}{1-\alpha} \cdot \frac{b_{t}^{*}+n_{t}}{1+\phi \cdot\left(\varepsilon+n_{t}\right)-x_{\mathcal{P}}^{*}} .
$$

Let $\widetilde{b}_{L, s}$ denote the smallest solution to:

$$
\tilde{b}_{L, s}=u_{s} \cdot \frac{\alpha}{1-\alpha} \cdot \frac{\tilde{b}_{L, s}+n_{s}}{1+\phi \cdot\left(\varepsilon+n_{s}\right)-x_{\mathcal{P}}^{*}},
$$

and let $\widetilde{b}_{L} \equiv \max _{s \in \mathcal{S}} \widetilde{b}_{L, s}$. Note that by construction $\tilde{b}_{L} \leq x_{\mathcal{P}}^{*}$. Now, note that in any state $s$, we have:

$$
1+\phi \cdot\left(\varepsilon+n_{s}\right)-x_{\mathcal{P}}^{*}=\frac{\alpha}{1-\alpha} \cdot u_{s} \cdot \frac{\widetilde{b}_{L, s}+n_{s}}{\widetilde{b}_{L, s}} .
$$

Plugging this into the monetary rule, we have:

$$
\begin{aligned}
\mu_{t+1}^{*}= & \frac{x_{\mathcal{P}}^{*} \cdot u_{s} \cdot \frac{\tilde{b}_{L, s}+n_{s}}{\widetilde{b}_{L, s}}-\left(b_{t}^{*}+n_{t}\right)}{x_{\mathcal{P}}^{*}-b_{t}^{*}} \\
= & \frac{x_{\mathcal{P}}^{*}-b_{t}^{*}+x_{\mathcal{P}}^{*} \cdot\left[u_{s} \cdot \frac{\widetilde{b}_{L, s}+n_{s}}{b_{L, s}}-1\right]-n_{t}}{x_{\mathcal{P}}^{*}-b_{t}^{*}} .
\end{aligned}
$$

Let $S_{\eta}=\left\{s: n_{s}=\eta\right\}$ denote the set of all states in the state space in which bubble creation is equal to some $\eta$. From Equation (A.34), for all $s, s^{\prime} \in S_{\eta} \subset \mathcal{S}$, we have:

$$
u_{s} \cdot \frac{\tilde{b}_{L, s}+\eta}{\widetilde{b}_{L, s}}=u_{s^{\prime}} \cdot \frac{\widetilde{b}_{L, s^{\prime}}+\eta}{\widetilde{b}_{L, s^{\prime}}} .
$$


Moreover, since $E_{t} u_{t+1}=1$, if there is a negative bubble return shock in some state, i.e. $u_{s}<1$, there must also be a positive one in another state, i.e., $u_{s^{\prime}}>1$. This implies that, for any $n_{t}=\eta$ and any $s \in S_{\eta} \subset \mathcal{S}$, we have:

$$
\begin{aligned}
x_{\mathcal{P}}^{*} \cdot\left[u_{s} \cdot \frac{\tilde{b}_{L, s}+\eta}{\widetilde{b}_{L, s}}-1\right]-\eta & =x_{\mathcal{P}}^{*} \cdot\left[u_{s^{\prime}} \cdot \frac{\tilde{b}_{L, s^{\prime}}+\eta}{\widetilde{b}_{L, s^{\prime}}}-1\right]-\eta \\
& \geq x_{\mathcal{P}}^{*} \cdot \frac{\eta}{\tilde{b}_{L, s^{\prime}}}-\eta \\
& \geq\left(\frac{\tilde{b}_{L}}{\widetilde{b}_{L, s^{\prime}}}-1\right) \cdot \eta>0
\end{aligned}
$$

where to obtain the last inequality, we used the fact that $\widetilde{b}_{L} \leq x_{\mathcal{P}}^{*}$. But then, by inspection of Equation (A.36), we see that $\mu_{t}^{*} \geq 1$ for all $t$ and $h^{t}$.

Acknowledgments. We thank Philippe Bacchetta, Wenxin Du, Jordi Gali, Marcus Hagedorn, Philippe Weil, Gregory Thwaites, and seminar/conference participants at Bank of Portugal, IMF, Humboldt Universitat, Nova Business School, Richmond Fed, Santa Clara University, Stanford University, Barcelona GSE Summer Forum, Conference on Banking, Monetary Policy and Macroeconomic Performance at Goethe Universitat Frankfurt, Research Forum on Macro-Finance at Bank of England, Annual Research Conference at Sciences Po, NBER Conference on Capital Flows and Debt in Emerging Markets, Transpyrenean Macro Workshop, SED Meetings in Warsaw, Conference on Monetary Policy and Financial Instability at Banque de France, and joint BoE, ECB, CEPR, CFM Conference on Credit Dynamics and the Macroeconomy. We acknowledge support from the Spanish Ministry of Economy and Competitiveness (grant ECO2014-54430-P), Generalitat de Catalunya (grant 2014SGR-830 AGAUR), and Spanish Ministry of Economy and Competitiveness, through the Severo Ochoa Programme for Centres of Excellence in R\&D (SEV-2015-0563). In addition, Martin and Ventura acknowledge support from the ERC (Consolidator Grant FP7-615651-MacroColl and Advanced Grant FP7-249588-ABEP), and Martin thanks the IMF Research Fellowship. Janko Heineken and Doruk Gökalp provided excellent research assistance. The views reflected here are those of the authors and not of the European Central Bank.

\section{Supplementary Data}

Supplementary data are available at Review of Economic Studies online.

\section{REFERENCES}

BACCHETTA, P., BENHIMA, K. AND KALANTZIS, Y. (2019), "Money and Capital in a Persistent Liquidity Trap", Journal of Monetary Economics, forthcoming.

BENHABIB, J., SCHMITT-GROHÉ, S. AND URIBE, M. (2001), "The Perils of Taylor Rules", Journal of Economic Theory, 96, 40-69.

BENIGNO, G. AND FORNARO, L. (2018), "Stagnation Traps", The Review of Economic Studies, 85, $1425-1470$.

BERNANKE, B. AND GERTLER, M. (1989), "Agency Costs, Net Worth, and Business Fluctuations", American Economic Review, 79, 14-31.

CABALlERO, R. AND FARHI, E. (2018), "The Safety Trap", The Review of Economic Studies, 85, $223-274$.

CABALlERO, R. J. AND KRISHNAMURTHY, A. (2006), "Bubbles and Capital Flow Volatility: Causes and Risk Management", Journal of Monetary Economics, 53, 35-53.

CARVALHO, V. M., MARTIN, A. AND VENTURA, J. (2012), "Understanding Bubbly Episodes", American Economic Review, 102, 95-100.

DEL NEGRO, M., EGGERTSSON, G., FERRERO, A. et al. (2017), “The Great Escape? A Quantitative Evaluation of the Fed's Liquidity Facilities", American Economic Review, 107, 824-57.

DI TELLA, S. (2020), "Risk Premia and the Real Effects of Money", American Economic Review, 110, 1995-2040.

EGGERTSSON, G. AND KRUGMAN, P. (2012), "Debt, Deleveraging, and the Liquidity Trap: A Fisher-minsky-koo Approach", The Quarterly Journal of Economics, 127, 1469-1513.

EGGERTSSON, G. AND WOODFORD, M. (2003), "The Zero Bound on Interest Rates and Optimal Monetary Policy", Brookings Papers on Economic Activity, 2003, 139-211.

EGGERTSSON, G. B., MEHROTRA, N. R. AND ROBBINS, J. A. (2019), "A Model of Secular Stagnation: Theory and Quantitative Evaluation”, American Economic Journal: Macroeconomics, 11, 1-48.

FARHI, E. AND GOURIO, F. (2018), "Accounting for Macro-finance Trends: Market Power, Intangibles, and Risk Premia", Brookings Papers on Economic Activity Fall 2018, 147-223.

FARHI, E. AND TIROLE, J. (2011), "Bubbly Liquidity", Review of Economic Studies, 79, 678-706.

GALÍ, J. (2009), Monetary Policy, Inflation, and the Business Cycle: An Introduction to the New Keynesian Framework (Princeton University Press).

GALÍ, J. (2014), Monetary Policy and Rational Asset Price Bubbles. The American Economic Review, 104, 721-752.

GALÍ, J. (2019), "Monetary Policy and Bubbles in a New Keynesian Model with Overlapping Generations", American Economic Journal: Macroeconomics, forthcoming. 
GERTLER, M. AND KARADI, P. (2011), “A Model of Unconventional Monetary Policy”, Journal of Monetary Economics, 58, 17-34.

GERTLER, M. AND KIYOTAKI, N. (2010), Financial Intermediation and Credit Policy in Business Cycle Analysis", in Friedman, B. M. and Woodford, M. (eds) Handbook of Monetary Economics, Vol. 3 (Elsevier) 547-599.

GUERRIERI, V. AND LORENZONI, G. (2012), "Liquidity and Trading Dynamics", Econometrica, 77, 1751-1790.

HANSEN, A. H. (1939), "Economic Progress and Declining Population Growth", The American Economic Review, 29, $1-15$.

KARABARBOUNIS, L. AND NEIMAN, B. (2014), "The Global Decline of the Labor Share”, The Quarterly Journal of Economics, 129, 61-103.

KIYOTAKI, N. AND MOORE, J. (1997), "Credit Cycles", The Journal of Political Economy, 105, 211-248.

KRISHNAMURTHY, A. AND VISSING-JORGENSEN, A. (2012), "The Aggregate Demand for Treasury Debt", Journal of Political Economy, 120, 233-267.

KRUGMAN, P. (1998), "It's baaack: Japan's Slump and the Return of the Liquidity Trap", Brookings Papers on Economic Activity, 1998, 137-205.

KRUGMAN, P. (2013), "Secular Stagnation, Coalmines, Bubbles, and Larry Summers" (New York Times, November 163).

MARTIN, A. AND VENTURA, J. (2012), "Economic Growth with Bubbles", American Economic Review, 102, 30333058.

MARTIN, A. AND VENTURA, J. (2015), "The International Transmission of Credit Bubbles: Theory and Policy", Journal of Monetary Economics, 76, S37-S56.

MARTIN, A. AND VENTURA, J. (2016), "Managing Credit Bubbles", Journal of the European Economic Association, 14, 753-789.

MARTIN, A. AND VENTURA, J. (2018), “The Macroeconomics of Rational Bubbles: A User's Guide”, Annual Review of Economics, 10, 505-539.

MIAO, J. AND WANG, P. (2012), "Bubbles and Total Factor Productivity", American Economic Review, 102, 82-87.

MIAO, J. AND WANG, P. (2018), "Asset Bubbles and Credit Constraints", American Economic Review, 108, 2590-2628.

OBSTFELD, M. AND ROGOFF, K. (1983), "Speculative Hyperinflations in Maximizing Models: Can We Rule Them Out?" Journal of Political Economy, 91, 675-687.

PIKETTY, T., SAEZ, E. AND ZUCMAN, G. (2018), "Distributional National Accounts: Methods and Estimates for the United States", The Quarterly Journal of Economics, 133, 553-609.

SAMUELSON, P. A. (1958), "An Exact Consumption-loan Model of Interest with or without the Social Contrivance of Money", Journal of Political Economy, 66, 467-482.

SUMMERS, L. (2013), "Why Stagnation Might Prove to be the New Normal" (The Financial Times).

TIROLE, J. (1985), “Asset Bubbles and Overlapping Generations", Econometrica, 53, 1499-1528.

WALLACE, N. (1981), "A Modigliani-Miller Theorem for Open-Market Operations", The American Economic Review, 71, 267-274.

WANG, P., MIAO, J. AND DONG, F. (2017), "Asset Bubbles and Monetary Policy" (Manuscript, Boston College).

WOODFORD, M. (2011), Interest and Prices: Foundations of a Theory of Monetary Policy (Princeton University Press). 